\title{
Prospects of targeted and immune therapies in SCLC
}

Citation for published version (APA):

Hendriks, L. E. L., Menis, J., \& Reck, M. (2019). Prospects of targeted and immune therapies in SCLC. Expert review of anticancer therapy, 19(2), 151-167. https://doi.org/10.1080/14737140.2019.1559057

Document status and date:

Published: 01/02/2019

DOI:

10.1080/14737140.2019.1559057

Document Version:

Publisher's PDF, also known as Version of record

Document license:

Taverne

Please check the document version of this publication:

- A submitted manuscript is the version of the article upon submission and before peer-review. There can be important differences between the submitted version and the official published version of record.

People interested in the research are advised to contact the author for the final version of the publication, or visit the DOI to the publisher's website.

- The final author version and the galley proof are versions of the publication after peer review.

- The final published version features the final layout of the paper including the volume, issue and page numbers.

Link to publication

\footnotetext{
General rights rights.

- You may freely distribute the URL identifying the publication in the public portal. please follow below link for the End User Agreement:

www.umlib.nl/taverne-license

Take down policy

If you believe that this document breaches copyright please contact us at:

repository@maastrichtuniversity.nl

providing details and we will investigate your claim.
}

Copyright and moral rights for the publications made accessible in the public portal are retained by the authors and/or other copyright owners and it is a condition of accessing publications that users recognise and abide by the legal requirements associated with these

- Users may download and print one copy of any publication from the public portal for the purpose of private study or research.

- You may not further distribute the material or use it for any profit-making activity or commercial gain

If the publication is distributed under the terms of Article $25 \mathrm{fa}$ of the Dutch Copyright Act, indicated by the "Taverne" license above, 


\title{
Prospects of targeted and immune therapies in SCLC
}

\author{
Lizza E. L. Hendriks ${ }^{\mathrm{a}, \mathrm{b}}$, Jessica Menis ${ }^{c}$ and Martin Reck ${ }^{\mathrm{d}}$
}

aDepartment of Pulmonary Diseases, GROW - School for Oncology and Developmental Biology, Maastricht University Medical Centre, Maastricht, the Netherlands; 'bepartment of Medical Oncology, Gustave Roussy, Institut d'Oncologie Thoracique (IOT), Gustave Roussy, Université Paris-Saclay, Villejuif, France; 'Medical Oncology, University of Padua and Veneto Institute of Oncology IOV - IRCCS, Padua, Italy; ${ }^{\mathrm{d} A i r w a y ~ R e s e a r c h ~ C e n t e r ~ N o r t h ~}$ (ARCN), German Center for Lung Research, LungenClinic, Grosshansdorf, Germany

\section{ABSTRACT}

Introduction: Small cell lung cancer (SCLC) is a tumor with a poor prognosis, often diagnosed in an advanced stage. Despite aggressive treatment of early and locally advanced disease, SCLC often relapses. First line chemotherapy provides good response rates in advanced disease, but progression free and overall survival are limited. New drugs such as some targeted therapies and immune therapies are promising in SCLC.

Areas covered: In this review, we discuss the preclinical rationale and trial data for targeted therapies and immune therapies in SCLC, with a specific focus on clinical trials.

Expert commentary: Lack of identification of clear prognostic and predictive biomarkers has limited the advances in treatment efficacy. This has most likely been the main cause of failure for compounds tested so far. Due to the highly mutational profile and the rapid growth pattern of SCLC, immunotherapy combined with chemotherapy seems the most promising treatment option. Concerning targeted agents, achievements made so far are small, but DLL3-antibodies or combinations of PARPi and immunotherapy could be very promising. These promising strategies also need testing in limited disease.

\section{ARTICLE HISTORY}

Received 30 July 2018

Accepted 10 December 2018

\section{KEYWORDS}

Checkpoint inhibitors; immune therapy; small cell lung cancer; targeted therapy; vaccination therapy

\section{Introduction}

Incidence of small-cell lung cancer (SCLC) has declined over the last years, especially in countries with effective smoking cessation programs (usually high-income countries); nevertheless, it still accounts for approximately $10-15 \%$ of all lung cancer cases [1]. Most importantly, SCLC is the sixth most common cause of cancer-related mortality [2] and its incidence is increasing in the low- and middle-income countries $[3,4]$.

The strongest risk factor for developing SCLC is smoking; in an epidemiologic study, only $2.5 \%$ of the SCLC occurred in neversmokers [5]. Smoking cessation results in a decreased risk, but the risk remains higher compared to never-smokers [6-8].

Low-dose computed tomography screening for SCLC has not proven to be effective because of the highly aggressive nature of the disease [9-11]: up to $86 \%$ is diagnosed at an advanced stage, median overall survival (OS) is only 20.6 months, and no survivors were found at 3 years in a screening trial [10].

Standard treatment for SCLC has not changed over the last 10-15 years both for limited disease (LD) and extensive disease (ED). Currently, advised treatment, by European Society for Medical Oncology (ESMO) guidelines, for patients with LD is chemoradiation followed by prophylactic cranial irradiation (PCI); surgery is an option in T1-T2, NO, and MO patients [12].

Concerning ED, standard of care is platinum-based doublet with etoposide (in Europe/US) or irinotecan (in Japan) for 4-6 cycles; $\mathrm{PCl}$ is an option in these patients [12]. Cisplatin can be substituted by carboplatin; as in a meta-analysis published in 2012 by Rossi et al., no differences in efficacy was found [13].

Despite the high response rate (RR), most patients relapse within 6 months. The only approved second-line treatment in Europe and the USA is topotecan either intravenous or oral (similar efficacy) $[14,15]$. For those patients that instead progress after 6 months, a valid option is rechallenge with a platinum-based regimen.

Among other possible options, paclitaxel showed a RR of $24-29 \%$ in two small studies $(N=21$ and $N=24)$, median OS was only 3.3 months in one trial and 5.8 months in the other trial $[16,17]$; temozolomide monotherapy showed a RR of $12-23 \%$ in two small trials, median OS was 5.8 months in both trials $[18,19]$. CAV still remains also an option although very limited due to its toxicity profile [12].

Amrubicin, approved in Japan, did not demonstrate an OS benefit compared to topotecan in the phase III European trial: median OS was 7.5 months for amrubicin and 7.8 months for topotecan (HR 0.88, $p=0.17$ ), although in a subset analysis including platinum-refractory patients a numerically, significant OS improvement was found (6.2 vs 5.7 months, HR 0.77 , $p=0.47$ ) [20].

In this review, we will focus on the current evidence for targeted agents and immunotherapy trials and also give some insight on the promising compounds that might hopefully change the poor prognosis of the SCLC patient population. 


\section{Targeted therapy in SCLC}

\subsection{Preclinical rationale}

\subsubsection{Molecular alterations}

The druggable alterations that are found in NSCLC are generally very rare in SCLC. For example, epidermal growth factor receptor $(E G F R)$, anaplastic lymphoma kinase, human epidermal growth factor receptor 2, CMET, v-RAF murine sarcoma viral oncogene homolog-B (BRAF), and c-ROS oncogene 1 (ROS1) mutations/translocations are rarely found in SCLC samples $[21,22]$. Alterations more often found in SCLC are aberrations in cell cycle regulation (e.g. CDKN2A, CDK4/6, TP53, RB1, Chk-1, Wee-1), receptor kinase signaling [e.g. stem-cell factor receptor tyrosine kinase (c-KIT), PI3K/AKT/mTOR, insulin-line growth factor receptor (IGFR1), fibroblast growth factor receptor 1 (FGFR1), PTEN, hedgehog signaling pathways], overexpression of the antiapoptotic proteins (e.g. BCL-2, found in $80 \%$ of SCLC), and alterations in DNA repair pathways [e.g. MYC amplification, overexpression of poly(ADP ribose) polymerase (PARP) enzymes, DNA alkyltransferase (O(6)-methylguanine-DNA methyltransferase (MGMT)) expression] [23-30]. In contrast to other tumors, mutations in DNA repair genes (such as BRCA1/2) were not associated with response to PARP inhibition in SCLC. However, Schlafen11 (SLFN11) which regulates response to DNA damage and replication stress is a possible predictive marker for response to PARP inhibition in SCLC, although prospective validation is needed [31]. Furthermore, epigenetic processes are also often dysregulated in SCLC (e.g. histone modifier mutations) [32]. An overview of the incidence of these alterations can be found in Sharp et al. [28]. Reduced SCLC tumor growth has been shown in preclinical models when the alterations mentioned above are targeted with monotherapies or combination therapies [33-40].

Another interesting target in SCLC is the NOTCH-signaling pathway, involved in early lung development and stem-cell self-renewal. NOTCH signaling can have oncogenic or tumorsuppressive effects and NOTCH can influence multiple oncogenic pathways. The function is dependent on the cellular content and tumor type; in neuro-endocrine tumors, NOTCH signaling suppresses oncogenesis and tumor growth [29,30,41-43]. One of the NOTCH inhibitory ligands is delta-like ligand 3 (DLL3), which is overexpressed in approximately $69 \%$ of SCLC but not in normal tissue $[29,30]$. This DLL3 overexpression is caused by achaetescute homologue 1 (ASCL1 or ASH-1) which regulates NOTCHsignaling components $[44,45]$. ASH-1 is a master regulator required for growth and survival of SCLC cells [46] and is expressed when the tumor-suppressor genes TP53 and RB1 are inactivated. Bi-allelic inactivation of the tumor-suppressor genes TP53 and RB1 occurs in almost al SCLC cases [29]. Preclinically, therapy with a DLL3-targeting antibody-drug conjugate (ADC) resulted in killing of SCLC cells, especially when they were expressing DLL3 [47].

SCLC can be divided into three distinct molecular subtypes by gene-expressing profiles, based on expression of ASH-1 and neurogenic differentiation factor 1 (NEUROD1, a neuronal master regulator) [44]. The classic SCLC form ('neuroendocrine high') is characterized by ASH-1 expression, the classic/variant type ('neuroendocrine variable') by high NEUROD1 expression with or without ASH-1 expression. The last form (variant/'neuroendocrine negative') is rare and has no expression of these two markers $[44,48,49]$. The different forms might respond different to immune therapies [50]. Last, although the majority of SCLC patients have mutant RB1, some have wild-type RB1, with varying percentages reported in the literature [29,51]. RB1 status is important, as patients with wild-type RB1 have lower responses to chemotherapy [51], and mutant RB1 status has been associated with sensitivity to DNA-damaging agents [52].

\subsubsection{Angiogenesis}

Besides the abovementioned alterations, the vasculature can also be targeted in SCLC as SCLC is a highly angiogenic tumor [53-55]. Compared with healthy controls, vascular endothelial growth factor (VEGF) and ang-2 (angiogenesis mediator) are increased in SCLC patients [56,57]. SCLC cell lines also express VEGF-receptor (VEGFR) 2 and 3 [54]. Furthermore, a high level of circulating VEGF is associated with poor OS and poor response to treatment $[58,59]$.

\subsubsection{Other targets}

Essential for tumor growth are sterols and isoprenoids that are produced by the mevalonate pathway; cholesterol is a component of this pathway (reviewed in Mullen et al.) [60]. Preclinically, it has been shown that statins can inhibit SCLC growth, either alone or in combination with chemotherapy [61].

Matrix metalloproteinases (MMPs) are a family of secreted proteins that are capable of digesting extracellular matrix and basement membrane components. MMP expression is often detected in SCLC and elevated expression has been associated with worse OS [62]. Preclinically, MMP inhibitors were able to reduce tumor growth $[63,64]$.

Trophoblast cell-surface antigen (Trop-2) is a glycoprotein that is elevated in many types of cancer, including SCLC. Elevated Trop-2 stimulates cancer growth and is associated with a worse prognosis. Preclinically, an ADC against Trop-2 showed activity in several cancers including SCLC [65].

\subsection{Trial data with targeted agents in LD-SCLC}

The majority of trials have evaluated targeted therapy in advanced SCLC. The few that have tested targeted therapies in LD-SCLC are summarized in Table 1; those that included LDSCLC as well as ED-SCLC patients are summarized only in this section and not in the ED-SCLC section. Ongoing trials are summarized in Table 2.

\subsubsection{Angiogenesis}

Thalidomide has antiangiogenic properties and has been evaluated in a randomized, double-blind, placebo-controlled trial $(N=724)$, including both LD- $(51 \%)$ and ED-SCLC patients. Primary end point was OS. Median OS was 10.5 months for placebo and 10.1 months for thalidomide [HR $(95 \% \mathrm{Cl}) 1.09$ (0.93-1.27); $p=0.28$. Patients treated with thalidomide had a significantly higher risk of having a tromboembolic event $(p<0.001)$ [66].

Vandetanib is another antiangiogenic agent as well as an EGFR inhibitor and was tested as maintenance therapy in a 


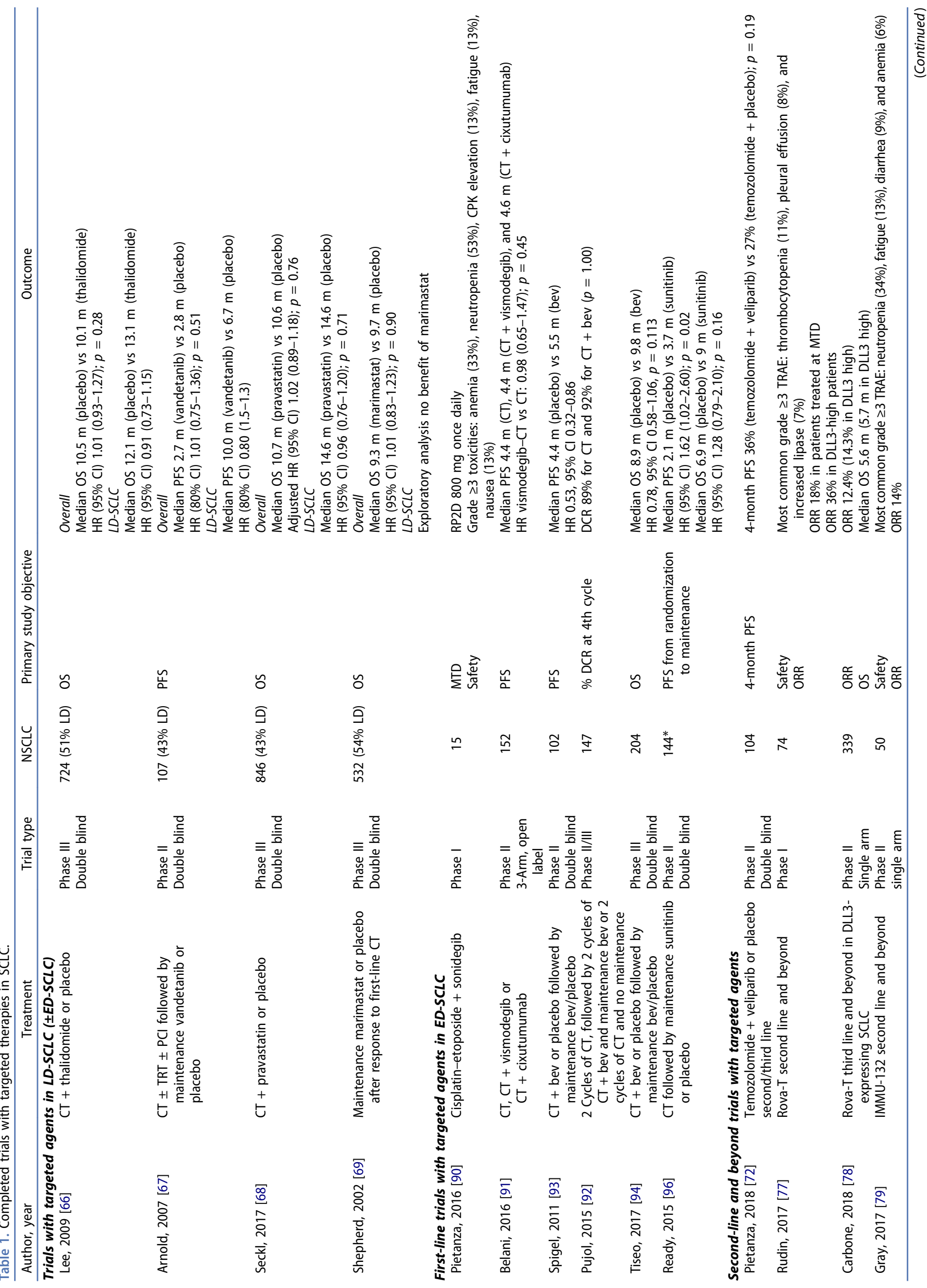




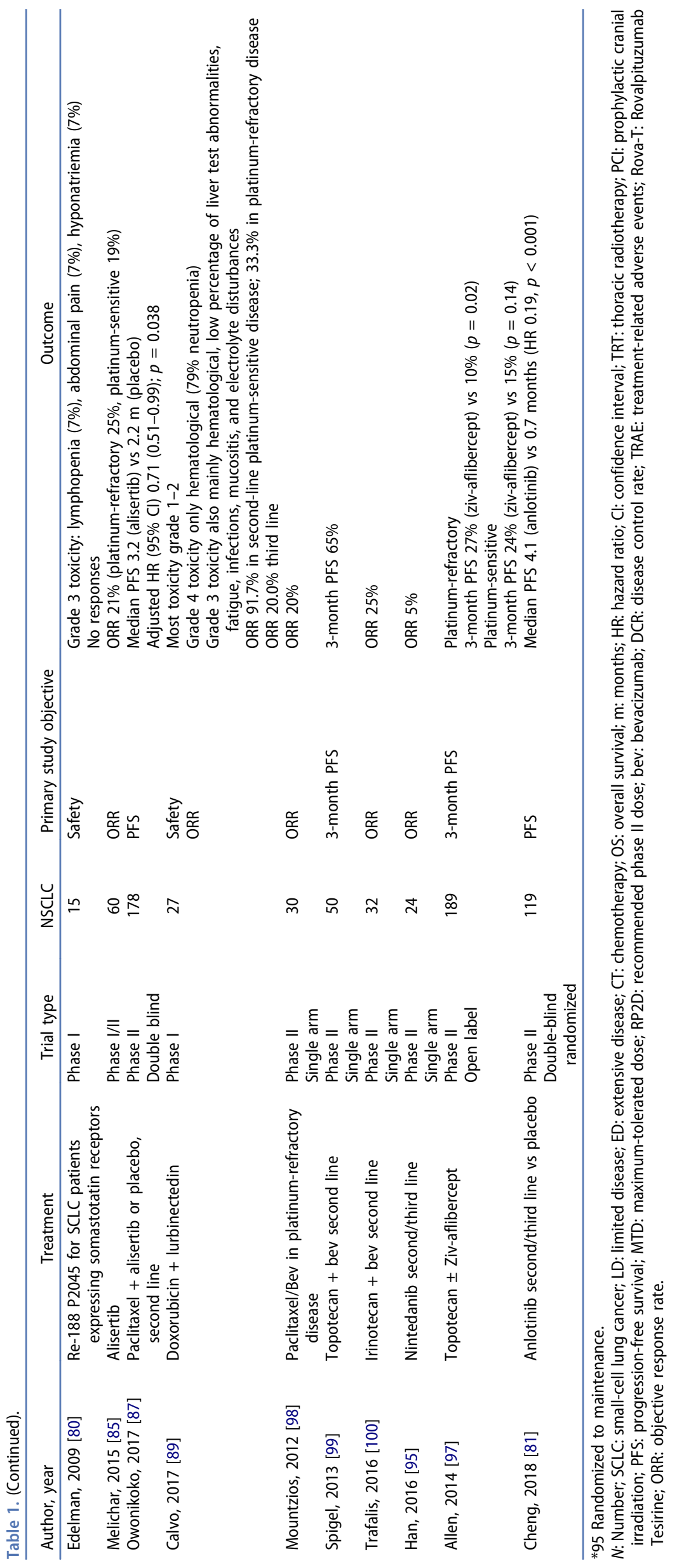




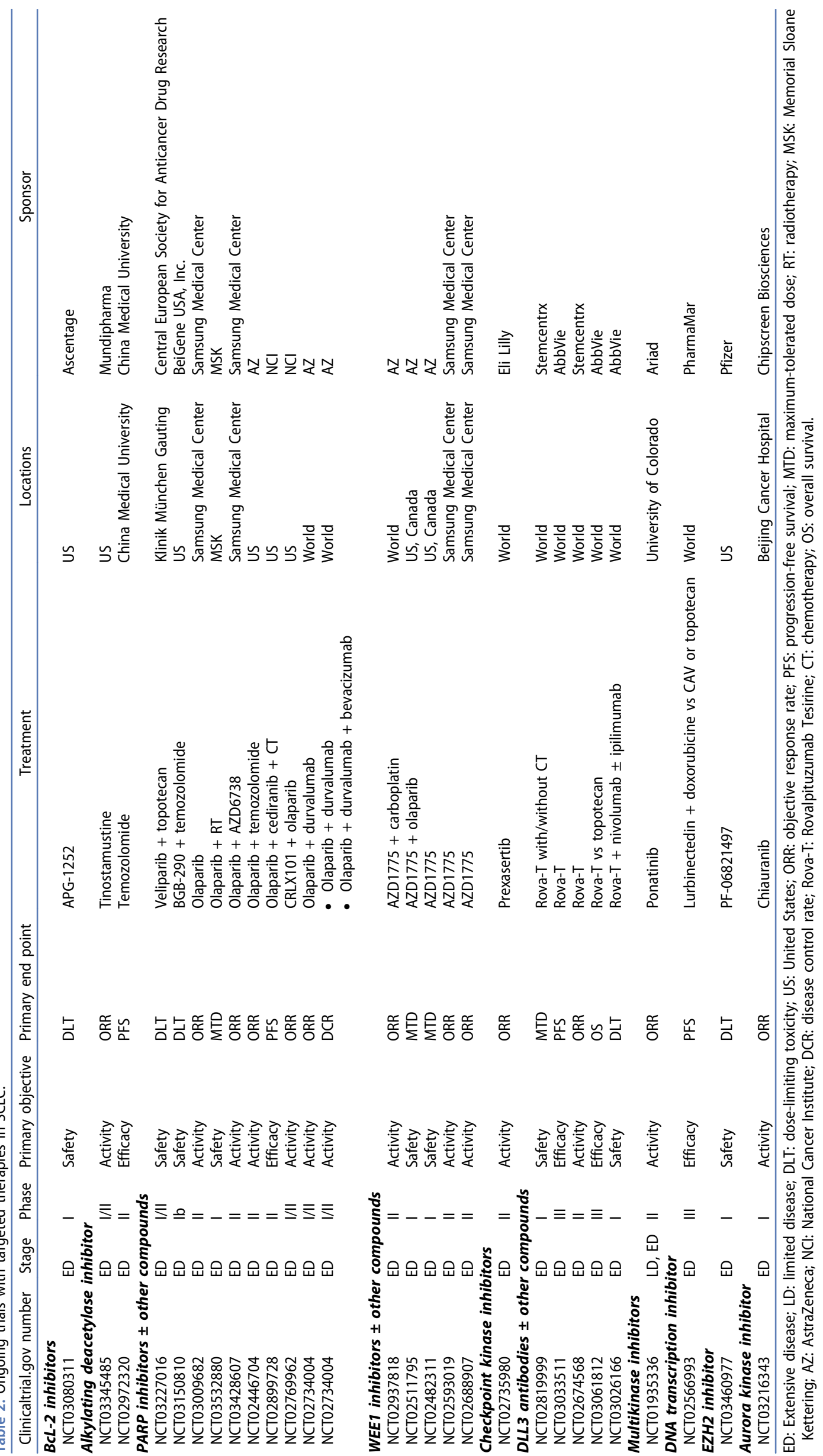


double-blind randomized phase II trial $(N=107)$, including LD$(43 \%)$ as well as ED-SCLC patients. Vandetanib did not improve progression-free survival (PFS) (primary end point): median 2.7 (vandetanib) versus 2.8 (placebo) months, respectively [HR $(80 \%$ Cl) $1.01(0.75-1.36) ; p=0.51$ ]. Median OS (a secondary end point) was also not significantly different: 10.6 months for vandetanib versus 11.9 for placebo [HR $(80 \% \mathrm{Cl}) 1.43(1.00$ 2.05); $p=0.9$ ] [67]. In both trials, also the subgroup of LD-SCLC patients did not derive benefit in the experimental arm $[66,67]$.

\subsubsection{Other targets}

In the multicenter, phase III, randomized, double-blind, placebo-controlled LUNGSTAR trial ( $N=846,43 \%$ LD-SCLC), pravastatin $40 \mathrm{mg}$ once daily or placebo was added to standardof-care first-line treatment (chemoradiation for LD-SCLC, platinum-etoposide for ED-SCLC). Pravastatin did not significantly improve OS (primary end point): for LD patients, median OS was 14.6 months for the pravastatin group and 14.6 months for the placebo group [HR $(95 \%$ Cl) $0.96 \quad(0.76-1.20)$; $p=0.71]$ [68].

Adjuvant marimastat (10 mg orally bid), a MMP inhibitor, has also been evaluated in a randomized, double-blind, placebocontrolled phase III trial ( $N=532,54 \%$ LD-SCLC). The trial was negative: median OS was 9.3 months for marimastat and 9.7 months for placebo [HR $(95 \%$ Cl) 1.01 (0.83-1.23); $p=0.90]$. In an unplanned analysis, there was also no survival benefit for marimastat for the LD patients [69].

\subsection{Trial data with targeted agents in ED-SCLC}

\subsubsection{Molecular alterations}

Tyrosine kinase receptor inhibitors inhibiting cell signaling and/ or apoptosis, with or without targeting angiogenesis (e.g. imatinib, dasatinib, gefitinib, linsitinib, sorafenib, sunitinib, cediranib, nintedanib, and pazopanib), all failed to show a significant benefit in SCLC (reviewed in Sharp et al. [28] and Baize et al. [70]). More promising targets are summarized in Table 1 and ongoing trials are summarized in Table 2.

\subsubsection{PARP inhibitors}

Temozolomide, an alkylating agent prodrug, showed some activity in a single-arm phase II trial $(N=64)$ : ORR was $23 \%$ in the platinum-sensitive cohort $(N=48)$ and $13 \%$ in the platinum refractory cohort. However, median PFS was only 3.5 months [18]. There was a trend to a higher ORR in patients with MGMT promotor methylation: $38 \%$ versus $7 \%(p=0.08)$.

Resistance to temozolomide can be PARP-based and there is preclinical evidence that PARP inhibitors (PARPi) act synergistically with temozolomide $[37,71]$. Therefore, veliparib (PARPi) $40 \mathrm{mg}$ orally twice daily on day 1-7 (28-day cycle) combined with temozolomide $150-200 \mathrm{mg} / \mathrm{m}^{2} /$ day orally once daily on dag 1-5 was tested in a randomized, double-blind, placebocontrolled phase II trial including ED-SCLC patients eligible for second/third-line treatment $(N=104)$. The trial was negative for its primary end point: 4-month PFS was $36 \%$ for veliparib/temozolomide and $27 \%$ for placebo/temozolomide $(p=0.19)$. Median OS was also not significantly different also (8.2 vs 7 months, respectively, 95\% Cl 5.3-9.5, $p=0.50$ ). Nevertheless, the combination resulted in a significantly higher ORR (39\%) compared to temozolomide-placebo (ORR 14\%) $(p=0.016)$ at the price of a higher percentage of grade 3 and 4 thrombocytopenia and neutropenia ( $50 \%$ vs $9 \%, 31 \%$ vs $7 \%$, respectively). In the exploratory biomarker analysis, in the subset of patients tested for PARP1 and/or MGMT methylation, no association between PARP1 positivity or MGMT methylation and ORR was found. Interestingly, patients with SLFN11 expression had improved PFS and OS with the veliparib/temozolomide combination [72]. As this analysis was exploratory, further evaluation is necessary to determine whether SLFN11 expression could serve as a biomarker to select SCLC patients for therapy with PARPi. Of note, a new biopsy should be obtained after chemotherapy, as SLFN11 decreases after exposure to chemotherapy [72].

Furthermore, it is possible that the combination with a PARPi and a PI3K-inhibitor would be a better combination, as SCLC can escape PARPi by upregulation of the PI3K-AKTmTOR pathway [33]. To the best of our knowledge, no trials have been completed or are currently ongoing with this combination. Everolimus (a PI3K-inhibitor) monotherapy had limited activity [73]. Trials with veliparib added to platinumetoposide are currently open (NCT01642251 and phase II part of NCT02289690), as veliparib potentiated the effect of platinum-etoposide preclinically and was shown to be safe in a phase I trial [74]. Olaparib is also a PARPi, and several trials of monotherapy olaparib or in combination with another drug are ongoing.

Another interesting combination is the combination of a PARPi and a Wee1 inhibitor: in a preclinical model, olaparib combined with the Wee1 inhibitor AZD1775 was more efficacious than cisplatin/etoposide in chemosensitive circulating tumor cell patient-derived explants (CDx), but responses diminished when the combination was tested at disease progression, suggestion that it should be tested in the clinic before disease progression. CDx with defects in DNA repair genes benefited most [75]. Several trials with monotherapy AZD1775 or AZD1775 combined with PARPi are ongoing in SCLC (Table 2).

Last, combination of a PARPi and a cell-cycle inhibitor is interesting as preclinically, prexasertib (LY2606368), a cellcycle checkpoint kinase CHK1 inhibitor, combined with olaparib or cisplatin augmented the effects of the other drug, especially when MYC amplification or overexpression was present [76]. A phase II study of monotherapy prexasertib is ongoing (NCT02735980).

\subsection{3. $A D C s$}

ADCs are antibodies directed at a defined antigen on a cancer cell, linked to a cytotoxic agent. Several are in development for SCLC treatment. The most advanced are Rovalpituzumab Tesirine (Rova-T) and Sacituzumab Govitecan (IMMU-132). Furthermore, Re-188 P2045, a somatostatin analog labeled with Rhenium-188, showed interesting survival in a phase I trial.

Rova-T recognizes the NOTCH ligand DLL3. In a phase I trial (NCT01901653), 82 lung cancer patients (74 SCLC, 8 LCNEC), who progressed after one or more lines of chemotherapy, were treated with escalating doses of single-agent Rova-T. About $18 \%$ of patients treated at the maximum-tolerated dose had a confirmed response and $50 \%$ had stable disease. Activity was higher in DLL3-high patients: ORR was $38 \%$ and 
disease control rate was $50 \%$. Median OS was 5.8 months in the DLL3-high group. The safety profile was manageable; most common grade $\geq 3$ toxicities were thrombocytopenia, pleural effusion, and increased lipase [77]. Based on these results, other trials with Rova-T were initiated, mainly in DLL3-high SCLC patients.

Results of the phase II TRINITY trial have recently been presented: 339 DLL3-expressing patients were included and were treated with Rova-T $0.3 \mathrm{mg} / \mathrm{kg}$ IV every 6 weeks, for 2 cycles (under specified conditions, retreatment was allowed). Primary end points were ORR and OS; a prespecified subgroup analysis included those with high DLL3 expression ( $\geq 75 \%$ of cells DLL3 positive). About $66 \%$ of patients completed the planned two doses of Rova-T, and ORR by independent review was $12.4 \%$ and was 14.3 in the DLL3-high group ( $N=238)$. In the DLL3-high group, $72 \%$ (third-line Rova-T) and $77 \%$ (fourth line) had disease control. Median OS $(95 \% \mathrm{Cl})$ was similar and was 5.6 (4.9-6.1) months in the total group and 5.7 (4.9-6.7) months in the DLL3-high group. Responses (best response and confirmed ORR) were associated with improved outcomes, as median OS was 9.8 months for responders. Forty percent of patients had grade 3 or higher treatment-related adverse event, of interest were photosensitivity reactions, pleural effusion, peripheral edema, and pericardial effusion. Other common toxicities were mainly gastrointestinal. Three percent had fatal events (edema, pneumonitis, ascites, drug-induced liver injury, pleural effusion, pneumothorax, respiratory failure, and sepsis) [78]. Two other methods of targeting DLL3 are a half-life extended bi-specific T-cell engager antibody construct (AMG 757) and adoptive chimeric antigen receptor T-cell therapy (AMG 119); phase I trials are currently enrolling (NCT03319940 and NCT03392064, respectively).

IMMU-132 contains the active metabolite of irinotecan, conjugated to an antibody that binds to Trop-2 which is widely expressed on SCLC. In a single-arm phase II trial (NCT01631552), 50 pretreated SCLC patients were treated with IMMU-132 8 or $10 \mathrm{mg} / \mathrm{kg}$ iv on days 1 and 8 of a 21day cycle. Primary end points were safety and ORR. Fourteen percent of patients had confirmed responses; median duration of response (DOR) was 5.7 months. Most common grade $\geq 3$ toxicities were neutropenia (34\%), fatigue (13\%), diarrhea (9\%), and anemia (6\%). Median OS was 7.5 months and was not statistically significantly different for those with platinum-sensitive or platinum-resistant disease in the overall population [79].

Re-188 P2045 was tested in a phase I trial, including advanced NSCLC and SCLC patients expressing somastotatin receptors ( $N=15$, of which 14 had $\geq 2$ previous treatment lines). No responses were seen, but $62.5 \%$ had stable disease for at least 8 weeks, and median OS was 11.5 months which is unexpectedly long in a pretreated population [80]. However, to the best of our knowledge, no trials are ongoing with this compound.

\subsubsection{FGFR inhibitors}

One trial has completed recruitment, although study results are not yet available: NCT02109016, a phase 2 study to assess if lucitanib is safe and effective (ORR) in the treatment of patients with advanced/metastatic lung cancer and FGFR, VEGF, or platelet-derived growth factor (PDGF)-related genetic alterations.

\subsubsection{Multikinase inhibitors}

Anlotinib is a multikinase inhibitor, especially inhibiting VEGFR, c-KIT, PDGFR, and FGFR. This drug showed promising clinical activity in third-line treatment and beyond the randomized, double-blind phase II ALTER1202 trial (NCT03059797). Patients were randomized 2:1 to anlotinib $12 \mathrm{mg}$ qd orally, days $1-14$ of a 21 -day schedule $(N=81)$, or placebo $(N=38)$. Median PFS (primary end point) was significantly prolonged in the anlotinib arm compared with the placebo arm: $4.1(95 \% \mathrm{Cl}$ 2.8-4.2) months versus $0.7(95 \% \mathrm{Cl} 0.7-0.8)$ months [HR 0.19 (95\% Cl 0.12-0.32), $p<0.001]$. OS data were not sufficiently mature at the date of the first report (WCLC, September 2018). Toxicity was manageable, with $35.8 \%$ versus $15.4 \%$ grade $3-5$ toxicity ( 1 death in the anlotinib group possibly related to anlotinib). The most common grade $\geq 3$ toxicity was hypertension (13.6\%), followed by hand-foot syndrome (4.9\%), hypertriglyceridemia (3.7\%), and lymphopenia (2.5\%) [81]. Anlotinib is currently being tested as maintenance therapy after four cycles of lobaplatin/etoposide in a randomized phase II trial (NCT03700359).

\subsubsection{Aurora kinase inhibitors}

Aurora kinase $A$ is necessary for mitotic spindle formation. MYC, a transcriptional regulator of aurora kinases $A$ and $B$, is amplified in $9-20 \%$ of SCLCs [82,83]; these SCLCs have a growth advantage in the absence of p53 [84]. Alisertib, an aurora kinase inhibitor, showed promising results in a phase I/II trial-included patients with pretreated solid cancer. Primary end point was ORR. Alisertib was given at a dose of $50 \mathrm{mg}$ twice daily, for 7 days followed by a break of 14 days. In the subgroup of SCLC patients ( $N=60$, of which 48 were response evaluable), an ORR of $21 \%$ was found. Thirty-six SCLC patients had platinum-sensitive disease and 12 had platinum-resistant disease; the highest ORR was found for platinum-refractory patients ( $25 \%$ vs $19 \%$ ). DOR was 3.1 months for platinumsensitive patients and 4.3 months for platinum-resistant patients. Most common grade 3-4 adverse events were neutropenia (43\%), leukopenia (21\%), and anemia (10\%) [85].

Aurora A functional single nucleotide polymorphisms were associated with improved outcome in patients with solid tumors treated with alisertib [86]. Based on these results, a randomized phase II study was initiated in advanced SCLC, evaluating second-line paclitaxel with alisertib or placebo. Patients were stratified according to platinum-sensitive or refractory disease and the presence of brain metastases. Primary end point was PFS. Alisertib was given at a dose of $40 \mathrm{mg}$ twice daily orally, 3 days on/4 days off. When combined with alisertib, paclitaxel was given at a dose of $60 \mathrm{mg} / \mathrm{m}^{2}$ iv on days 1,8 , and 15 of a 28-day schedule. When combined with placebo, paclitaxel was given a dose of $80 \mathrm{mg} / \mathrm{m}^{2}$. A total of 178 patients were enrolled: median PFS was significantly higher in the investigational arm and was 3.2 versus 2.2 months [corrected HR $(95 \% \mathrm{Cl}) 0.71(0.51-0.99) ; p=0.038]$. In the platinumresistant group $(N=109)$, median PFS was also significantly higher in the investigational arm: 2.9 vs 1.6 months [HR $(95 \% \mathrm{Cl})$ 
$0.66(0.44-0.98) ; p=0.037]$. ORR was slightly higher in the alisertib/paclitaxel group: $22 \%$ versus $18 \%$. There was a trend to a significantly higher median OS in the investigational arm: 6.9 versus 5.6 months [HR $((95 \% \mathrm{Cl}) 0.73(0.52-1.02) ; p=0.064]$. Treatment-related grade $\geq 3$ adverse events were higher in the alisertib/paclitaxel group: $67 \%$ versus $25 \%$; main adverse events (all grades) were hematological and gastrointestinal. However, health-related quality of life was similar for both groups. In an exploratory analysis, patients with c-MYC expression benefited most from the combination while the opposite was found for the c-MYC-negative group. For the c-MYC-positive group, median PFS was 4.6 months for the combination and 2.3 months for paclitaxel [HR $(95 \% \mathrm{Cl}) 0.29(0.12-0.72)]$. For the c-MYC-negative groups, median PFS was 3.3 and 5.2 months, respectively [HR (95\% Cl) 11.9 (1.52-91.2)] [87].

Barasertib (AZD1152), another aurora kinase inhibitor, showed promising preclinical results in SCLC [88], and only one trial is ongoing NCT01935336 (Table 2).

\subsubsection{Lurbinectedin}

Lurbinectedin inhibits active transcription in tumor cells and acts synergistically with doxorubicin. In a phase I trial including relapsed SCLC patients, recommended phase II dose was doxorubicin $50 \mathrm{mg} / \mathrm{m}^{2}$ iv on day 1 of a 21-day schedule and lurbinectedin $4.0-\mathrm{mg}$ flat dose iv on the same day. After reaching a cumulative dose of $450 \mathrm{mg} / \mathrm{m}^{2}$ doxorubicin, patients were switched to lurbinectedin 7.0-mg flat dose to avoid doxorubicin cardiomyopathy. Twenty-seven SCLC patients were evaluable. Toxicity profile was manageable; grade 4 toxicities were only hematological (79\% neutropenia), grade 3 toxicities were also mainly hematological, with also in a low percentage of patients liver test abnormalities, fatigue, infections, mucositis, and electrolyte disturbances. Second-line RR in platinum-sensitive disease were as high as $91.7 \%$ with a median PFS of 5.8 months; in platinum-resistant disease, RR was $33.3 \%$ with a median PFS of 3.5 months. Third-line RR was $20 \%$, with a median PFS of 1.2 months [89]. Lurbinectedin plus doxorubicin is currently compared to cyclophosphamide/doxorubicin/vincristin or topotecan in the ATLANTIS trial (NCT02566993).

\subsubsection{Stem-cell inhibitors}

Hedgehog inhibitors have also been evaluated in SCLC as the Hedgehog pathway has been implicated in SCLC tumor initiation and progression. In a phase I trial $(N=15$ newly diagnosed ED-SCLC patients), the hedgehog inhibitor sonidegib (LDE225) was combined with cisplatin/etoposide. About $800 \mathrm{mg}$ sonidegib daily was the recommended phase II dose. The most common grade 3 toxicities were anemia, neutropenia, CPK elevation, nausea, and fatigue. About $79 \%$ of patients had partial responses, and one patient with SOX2 amplification (reported to drive hedgehog signaling) remained progression free on maintenance sonidegib after 27 months [90]. Currently, no trials are ongoing on clinicaltrials.gov in SCLC.

Vismodegib, another hedgehog inhibitor, was tested in a randomized phase II trial (E1508), including 152 treatmentnaive advanced SCLC patients. Patients were randomized to standard chemotherapy, or standard chemotherapy combined with vismodegib $150 \mathrm{mg}$ /day orally or cixutumumab (insulinlike growth factor 1 receptor antibody). Primary end point was
PFS: the trial was negative with a HR $(95 \% \mathrm{Cl})$ for vismodegibchemo versus chemo: $0.98(0.65-1.47)(p=0.45)$. The addition of vismodegib did not increase the percentage of grade $\geq 3$ adverse events [91].

One more trial has completed recruitment but results are not yet available: NCT01579929, a phase I trial of the combination of LDE225, with etoposide and cisplatin as first-line treatment of ED-SCLC.

\subsubsection{Angiogenesis inhibition}

Several trials have attempted to incorporate an angiogenesis inhibitor in the treatment of SCLC but all failed to show an OS improvement despite sometimes an improvement in PFS.

Adding bevacizumab after response to two cycles of induction chemotherapy did not result in an improved median PFS in the IFCT 0802-phase II-III trial (NCT00930891) [92]. Based on, among others, the positive PFS results of the phase II SALUTE trial (NCT00403403, first-line chemotherapy \pm bevacizumab, followed by maintenance bevacizumab or placebo) [93], the phase III GOIRC-AIFA FARM6PMFJM trial (EudraCT No. 2007-007949-13, $N=204$ ) was launched, with a similar design as the SALUTE trial. The study failed its primary end point as median OS was 8.9 months for the placebo group and 9.8 months for the bevacizumab group ( $\mathrm{HR} 0.78,95 \% \mathrm{Cl} 0.58-1.06, p=0.113$ ). However, in a subgroup analysis, patients who received maintenance bevacizumab (43\% in the $\mathrm{EP}+$ bevacizumab group) had a statistically significant superior OS; so, continuation of an angiogenesis inhibitor across all lines might be an option [94]. Trials with other angiogenesis inhibitors (nintedanib, thalidomide, sunitinib, vandetanib) also failed to improve OS $[66,67,95,96]$. Based on these results, an angiogenesis inhibitor should only be administered to SCLC patients in the context of a clinical trial. Ziv-aflibercept binds circulating VEGF and might represent a new treatment option to improve outcome in SCLC. However, when added to topotecan in a phase II trial, only PFS but not OS improved, at a cost of increased toxicity [97]. Bevacizumab added to paclitaxel, topotecan, or irinotecan also failed to improve outcome in relapsed SCLC patients [98-100].

\section{Immunotherapy in SCLC}

\subsection{Preclinical rationale}

SCLC has a high rate of somatic mutations: non-synonymous mutation rates of up to 8.6 mutations per million base pairs have been found [29,32]. They are often induced by smoking: benzo(a)pyrene (a carcinogenic compound of tobacco) and its active metabolite covalently binds to DNA, which can result in a DNA synthesis block leading to aberrant centrosome amplification. In turn, this can lead to abrogated p53 function and chromosome $3 p$ deletion (which contains multiple tumor suppressor genes) [101-103]. This loss of tumor suppressor genes leads to increased mutagenesis. In $25 \%$ of SCLC patients, C: $\mathrm{G}>\mathrm{A}: \mathrm{T}$ transversions are found and they are an indication of heavy smoking $[29,104]$. Moreover, aberration of the intrinsic apoptotic pathway by inversion of the $\mathrm{Bcl}-2 / \mathrm{Bax}$ ratio results in further tumor growth [105]. Another signature found in SCLC which is linked to smoking and an increased mutagenesis is 
the apolipoprotein B mRNA editing enzyme, catalytic polypeptide-like (APOBEC) signature [106].

A high tumor mutational burden (TMB) has been associated with a favorable outcome when treated with immune checkpoint inhibitors. As SCLC has a high mutational burden, this provides opportunities for the immune system to recognize and attack the tumor cells [107]. Furthermore, approximately $15-30 \%$ of SCLCs express PD-L1 [108], and PD-L1 expression is often associated with higher RR in other tumors such as NSCLC [109]. Evidence that SCLC induces an immune response can be found in the relatively high incidence of paraneoplastic syndromes neoplastic-trigged autoimmune diseases in SCLC [110]. Moreover, SCLC patients in which immune activity is shown have a better outcome. For example, a higher $\mathrm{CD}_{4} 5^{+} \mathrm{T}$-cell count was associated with improved prognosis (irrespective of stage and performance status) [111]. High effector T-cell counts were more often found in LD-SCLC compared to ED-SCLC, and higher effector-to-regulatory $\mathrm{T}$-cell ratios were associated with improved outcome $[112,113]$. Immune checkpoint inhibitors are now incorporated in the treatment strategy of advanced NSCLC, either in first line or beyond [109,114-116]. Furthermore, in the PACIFIC trial (NCT02125461) maintenance, durvalumab (anti-PD-L1 antibody) showed a PFS benefit in stage III NSCLC patients treated with concurrent CRT, compared to placebo [117]. Trial data for SCLC are discussed below.

\subsection{Trial data with immunotherapy in LD-SCLC}

Currently, there are only completed vaccination trials and interferon trials, but no completed checkpoint inhibitor trials in LD-SCLC. Results from trials including LD as well as ED-SCLC patients will be discussed in the LD-SCLC section. Completed trials are summarized in Table 3 and ongoing trials are summarized in Table 4.

\subsubsection{Vaccination trials in $L D-S C L C$}

So far, results with vaccination have been disappointing. In a randomized phase III trial, LD-SCLC patients responding to chemoradiation were randomized between five vaccinations of Bec2 (2.5 mg)/BCG vaccine or observation. Bec2 is an antiidiotypic antibody that mimics GD3. GD3 is expressed on the surface of tumor cells. Primary end point was OS and 515 patients were randomized. The study was negative for its primary end point: median OS was 14.3 months for the observation arm and 16.5 months for the vaccination arm [HR $(95 \% \mathrm{Cl})$ 1.12 (0.91-1.37); $p=0.28$ ] [118].

In a phase I trial $(N=16)$, vaccination of SCLC patients (LD and ED-SCLC) with a major response to their initial therapy with synthetic fucosyl GM-1 conjugated to keyhole limpet hemocyanin at different dose levels was safe and induced an IgM-antibody response. However, no radiological responses were observed [119]. Another phase I trial vaccinated SCLC patients ( $N=18, \mathrm{LD}$ and ED-SCLC) responding to initial therapy, with a polySA vaccine. PolySA is a polymer side chain bound to the neural cell adhesion molecule that is extensively expressed on the surface of SCLC cells. The vaccine was safe and antibody responses were documented but radiological responses were not provided. Median OS was 22.9 months rather encouraging in this patient population [120].

The two ongoing vaccination trials in LD-SCLC have been terminated: NCT00776295: autologous SCT followed by dendritic cell p53 vaccination, terminated because of low accrual; NCT00045617: Chemoradiation and monoclonal antibody $11 \mathrm{D} 10$ or anti-idiotype monoclonal antibody GD2 anti-idiotype vaccine, terminated because of lack of drug availability.

\subsubsection{Immunotherapy trials in LD-SCLC}

Interferon (IFN) therapy has been evaluated in SCLC. IFNs have immunoregulatory, antiangiogenic, and antiproliferative effects. In a randomized phase II trial including 164 chemo-naive SCLC patients (62 LD-SCLC), patients were randomized to chemotherapy alone (group A), or chemotherapy combined with IFN-alfa (group B), IFN-gamma (group C), or both IFN-alfa and IFN-gamma (group D). The trial was negative for its primary end point: median OS for group A-D was 10.0, 10.3, 8.3, and 11 months, respectively $(p>0.05)$. When compared to the other groups, median OS was significantly higher for LD-SCLC patients treated in group B: median OS for group B was 34 versus 19 months for group A ( $p=0.039), 13.6$ months for group $C(p<0.005)$, and 17 months for group $D(p=0.038)$. However, number of LD-SCLC patients per group was small [121].

\subsubsection{Checkpoint inhibitors}

The concept of maintenance checkpoint inhibition is currently also tested in limited-stage SCLC in several trials; these are summarized in Table 4.

\subsection{Trial data with immunotherapy in ED-SCLC}

\subsubsection{Vaccination trials in ED-SCLC}

Besides the trials that included LD-SCLC as well as ED-SCLC (summarized in the LD-SCLC section), three other vaccination trials included only ED-SCLC patients. In a single-arm phase II trial ( $N=10$ pretreated SCLC patients), a personalized peptide vaccination was tested. The antigens in the vaccine were selected based on preexisting host immunity. The vaccine was administered weekly for 6 weeks and biweekly thereafter. Four patients discontinued during the weekly vaccination due to rapid disease progression; for the other six patients, peptidespecific immunological boosting was observed. At data-lock, two patients were still alive (survival 24.5 and 10 months); survival of the other patients was 25.0, 9.5, 6.5, and 6 months [122]. A similar phase II study included 46 ED-SCLC patients (pretreated and treatment-naive). The treatment was safe, and median OS was improved in those with increased IgG responses to a greater number of nonvaccinated peptides after the second cycle of vaccination (40.7 vs 12.6 months, $p=0.010$ ) [123].

As the p53 gene is mutated in approximately $90 \%$ of SCLC, a vaccine consisting of dendritic cells transduced with the fulllength wild-type p53 gene delivered via an adenoviral vector has been evaluated in ED-SCLC patients $(N=29)$. Vaccines were given at two-weekly intervals. About $57 \%$ had p53-specific T-cell responses, but only one patient responded clinically while the others progressed. Interestingly, $62 \%$ of patients responded to chemotherapy that immediately followed the 


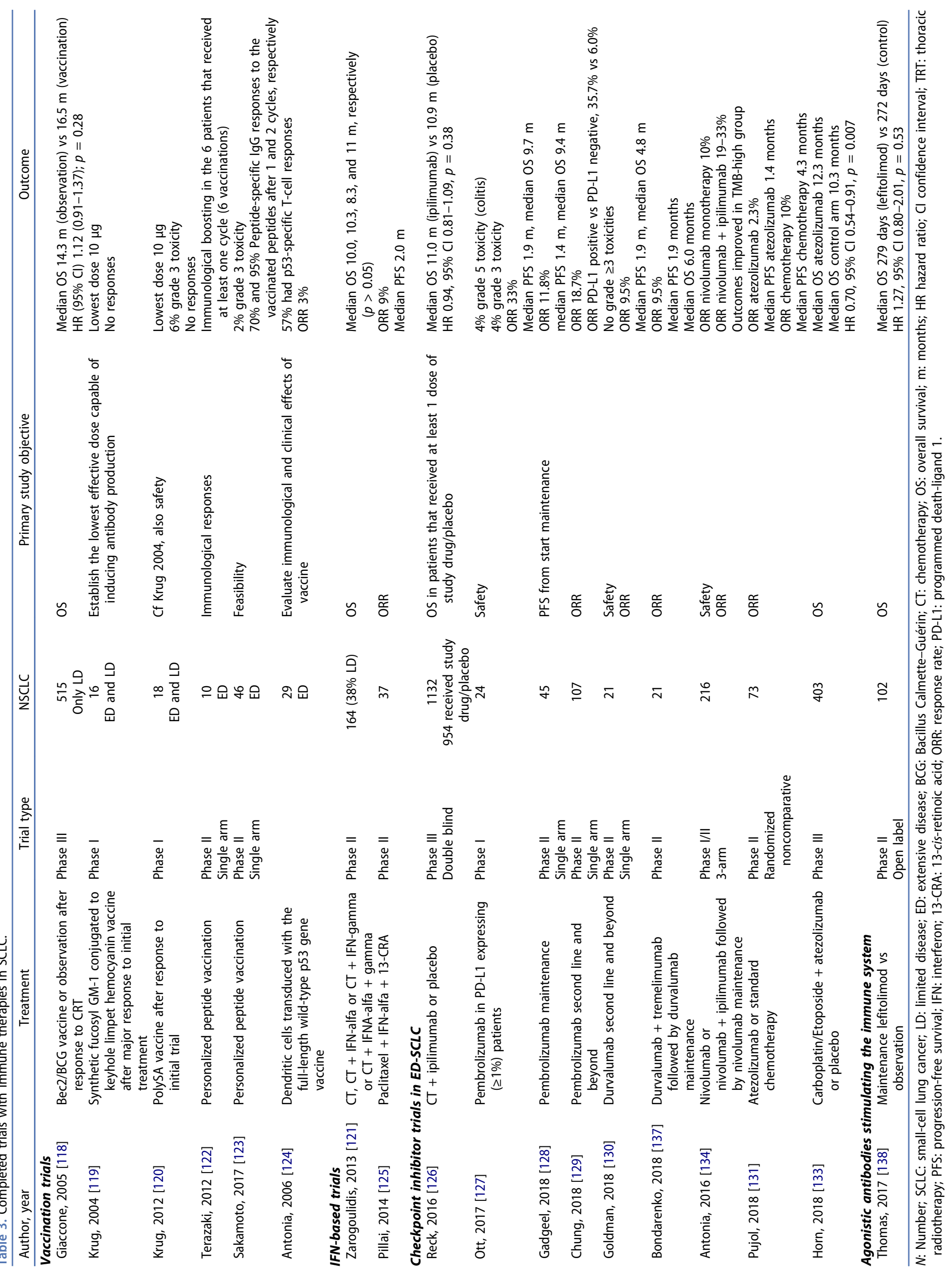




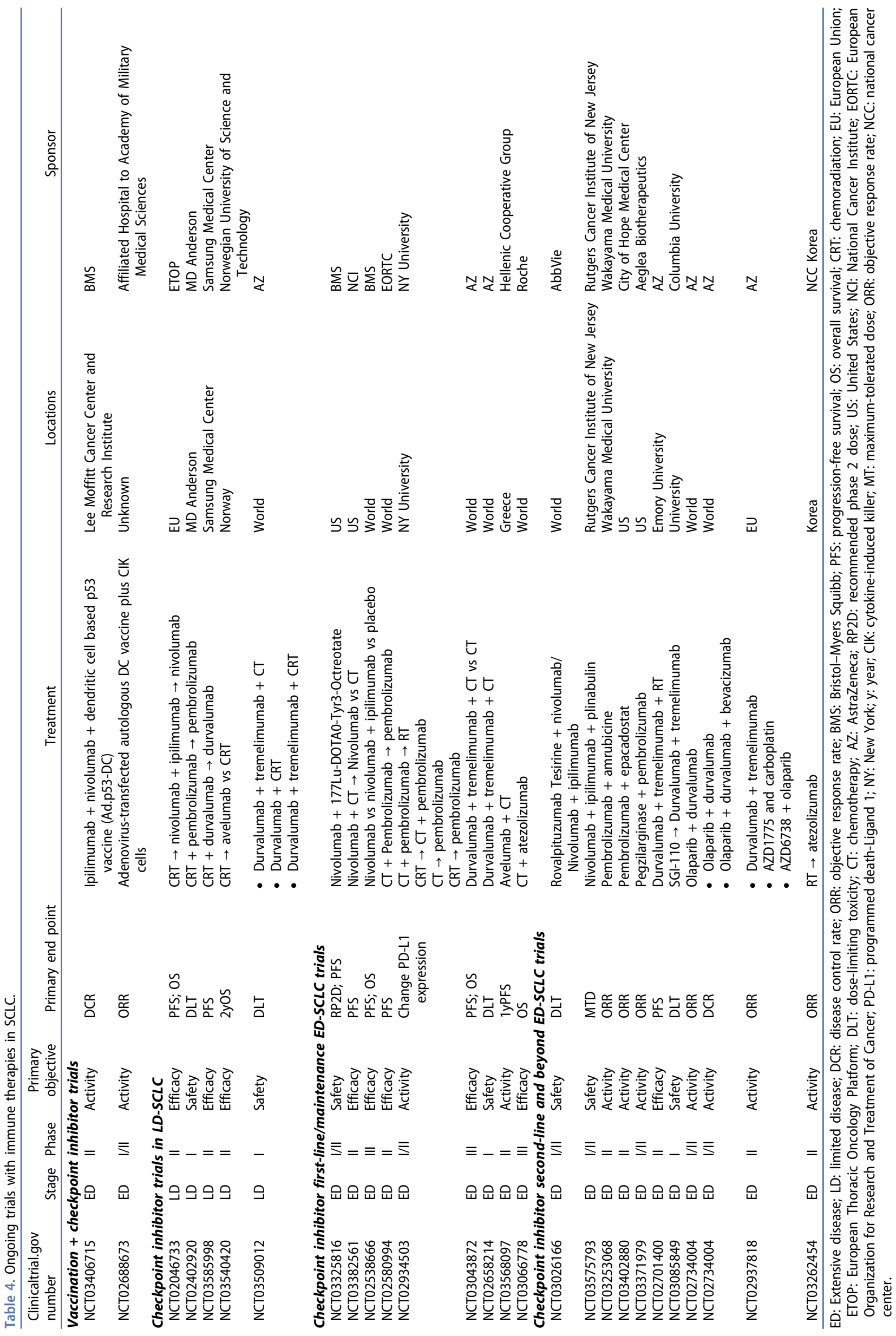


vaccination and responses were linked to induction of immunologic response to vaccination [124].

Several other vaccination trials are ongoing (Table 4).

\subsubsection{Immunotherapy trials}

As described in Section 2, trials with monotherapy Bcl-2 inhibition have been disappointing. In a phase II trial, IFN-alfa was added to the $\mathrm{Bcl}$-2-modifying agent 13-cis-retinoic acid (13CRA) and paclitaxel. Primary end point was ORR. Thirty-seven relapsed ED-SCLCs were enrolled and were treated with IFN-alfa (6 million units $/ \mathrm{m}^{2}$ subcutaneously) and 13-CRA $1 \mathrm{mg} / \mathrm{kg}$ days 1 and 2, and paclitaxel $75 \mathrm{mg} / \mathrm{m}^{2}$ iv on day 2 of each week for 6 weeks of an 8-week schedule. ORR was only $9 \%$ and PFS was only 2 months. Therefore, this combination is not further studied [125].

Checkpoint inhibitors (anti-PD-(L)1 and anti-CTLA4) have shown efficacy in SCLC in some (early phase) trials but other trials were negative. Results are summarized below.

Ipilimumab, a CTLA-4 inhibitor, did not result in an improved OS when added to platinum-etoposide in a firstline, double-blind, randomized phase III trial (NCT01450761). Primary end point was OS among patients that received at least one dose of study therapy. About 1132 treatment-naive ED-SCLCs were randomized to platinum-doublet chemotherapy with phased ipilimumab $10 \mathrm{mg} / \mathrm{kg}$ every 3 weeks (start at cycle 3 of chemotherapy till cycle 6). A total of 954 patients received at least 1 dose of ipilimumab/placebo. The trial was negative: median OS was 11.0 months for the experimental arm and 10.9 months for the standard treatment (HR 0.94, 95\% Cl 0.81-1.09, $p=0.38$ ). Except for diarrhea, rash, and colitis, rates and severity of treatment-related adverse-events were similar for both groups. However, treatment discontinuation occurred more often in the investigational arm (18\% vs 2\%) [126].

A phase I trial (KEYNOTE-028, NCT02054806) with pembrolizumab (PD-L1 inhibitor, $10 \mathrm{mg} / \mathrm{kg}$ every 2 weeks for up to 24 weeks) showed promising results in pretreated, PD-L1 expressing ( $\geq 1 \%)$ SCLC patients $(N=24)$. ORR was $33 \%$, median PFS was only 1.9 months but response was durable in responding patients (DOR 19.4 months). Median OS was 9.7 months. One patient had a grade 5 colitis, and another had a grade 3 bilirubin elevation. No other grade 3-5 adverse events were observed [127]. However, pembrolizumab maintenance therapy failed to improve PFS in a single-arm, phase II trial (NCT02359091) with 45 patients. Median PFS was only 1.4 months, RR was $11.8 \%$, and median OS was 9.6 months. The small subgroup of PD-L1-positive patients $(N=9)$ had a higher PFS compared with the PD-L1-negative patients (6.5 vs 1.3 months) [128]. Pembrolizumab monotherapy (200 mg iv every 3 weeks for up to 2 years) was also evaluated in the second-line and beyond phase II basket study KEYNOTE-158. Patients were selected regardless of biomarker status. Primary end point was ORR. About 107 patients were enrolled in the SCLC cohort, and $14 \%$ was PD-L1 positive $(\geq 1 \%)$. ORR was $18.7 \%$ and $30 \%$ had disease control. ORR was higher in the PD-L1 positive cohort $(N=42)$ compared to the PD-L1 negative cohort $(N=50)$ and was $35.7 \%$ vs $6.0 \%$. Median DOR was not reached; median PFS was 2.0 months and was similar for both PD-L1 status cohorts. Median OS was higher for the
PD-L1-positive cohort and was 14.9 vs 5.9 months. About $13 \%$ had grade 3-4 treatment-related adverse events [129].

Durvalumab monotherapy (10 mg/kg iv every 2 weeks for up to 12 months) has also been evaluated in a phase $\mathrm{I} / \mathrm{II}$ trial including a cohort of relapsed, unselected SCLC patients $(N=21)$. ORR was only $9.5 \%$; median PFS was 1.5 months with a median OS of 4.8 months. However, DOR for the two responding patients was 14.6 and $29.5+$ months. No new safety signals were observed [130]. Last, atezolizumab monotherapy (1200 mg iv every 3 weeks) has been compared to standard chemotherapy as second-line treatment for ED-SCLC in the randomized, noncomparative phase II IFCT-1603 trial $(N=73)$. For atezolizumab, ORR was $2.3 \%$ with a median PFS of 1.4 months. For chemotherapy, ORR was $10 \%$ with a median PFS of 4.3 months [131].

It is possible that the limited tumor expression of PD-L1 combined with an exhausted immune cell phenotype contributes to the limited activity of monotherapy checkpoint inhibition [132]. The combination of PD-L1 inhibition with chemotherapy or CTLA-4 inhibition is more promising in SCLC. The combination of PD-L1 inhibition with chemotherapy improved OS of treatment-naive ED-SCLC $(N=403)$ in the randomized phase III IMpower 133 trial. Patients were randomized between carboplatin/etoposide/atezolizumab followed by maintenance atezolizumab or carboplatin/etoposide/placebo followed by maintenance placebo. Atezolizumab was given at a flat dose of $1200 \mathrm{mg}$ every 3 weeks. Median OS was 12.3 months for the atezolizumab arm and 10.3 months for the control arm (HR 0.70,95\% Cl 0.54-0.91, $p=0.007$ ). Compared to previous safety findings of the individual agents, no new safety signals were observed with the combination [133]. The phase III KEYNOTE 604 trial (NCT03066778) with a similar design as the IMpower133 (pembrolizumab $200 \mathrm{mg}$ flat dose instead of atezolizumab) is currently enrolling patients.

Data with PD-L1 and CTLA-4 inhibition combined are also interesting. For example, in the non-randomized phase I/II CHECKMATE-032 trial (NCT01928394) including relapsed SCLC patients $(N=216)$, RR with monotherapy nivolumab (3 mg/kg every 2 weeks) was $10 \%$, but RR with nivolumab plus ipilimumab ( 1 plus $1 \mathrm{mg} / \mathrm{kg}$, 1 plus $3 \mathrm{mg} / \mathrm{kg}$, or 3 plus $1 \mathrm{mg} / \mathrm{kg}$ iv every 3 weeks for 4 cycles followed by nivolumab monotherapy $3 \mathrm{mg} / \mathrm{kg}$ every 2 weeks) ranged from 19\% to $33 \%$. Responses were in both groups durable; median DOR was 14.2-17.9 months. PD-L1 expression was not associated with response [134]. In the randomized expansion cohort of this trial, similar results were obtained. Grade 3-4 adverse events were higher with the combination therapy [135]. In an exploratory analysis of this trial, 211 patients (53\%) were evaluable for TMB (measured with whole exome sequencing) and patients were divided in tertiles according to TMB value. Outcomes in the TMB-evaluable population were similar compared with the intention-to-treat population. ORR for high TMB patients compared to low/medium TMB patients was higher in the nivolumab monotherapy group and in the nivolumab/ipilimumab group ( $21.3 \%$ vs $4.8-6.8 \%$ and $46.2 \%$ vs 22.2-16.0\%, respectively). For nivolumab monotherapy, median PFS was similar across the TMB tertiles (1.3, 1.3, and 1.4 months). However, for nivolumab/ipilimumab, median PFS was higher for the TMB-high group compared with the 
TMB low/medium groups (7.8 vs $1.5-1.3$ months). Median OS was also higher for the nivolumab/ipilimumab TMB-high group: 22.0 vs 3.4-3.6 months [136]. In the phase II BALTIC trial (cohort A), durvalumab $1500 \mathrm{mg}$ iv and tremelimumab $75 \mathrm{mg}$ iv every 4 weeks for up to 4 months, followed by maintenance durvalumab $1500 \mathrm{mg}$ iv every 4 weeks were evaluated in platinum-refractory/resistant ED-SCLC $(N=21)$. ORR was $9.5 \%$ with a median PFS of 1.9 months and a median OS of 6.0 months. Twelve-month OS was $32.7 \%$. Grade $\geq 3$ treatment-related AEs occurred in $9.5 \%$, including one fatal hemorrhagic enterocolitis [137].

PD-L1 and CTLA-4 inhibitors combined with chemotherapy are currently being tested in the phase III CASPIAN trial (NCT03043872, platinum/etoposide vs durvalumab/platinum/ etoposide vs durvalumab/tremelimumab/platinum/etoposide).

Furthermore, multiple other checkpoint inhibitor trials are ongoing in SCLC and are summarized in Table 4.

Agonistic antibodies are another method of stimulating the immune system. Lefitolimod, a TLR9 agonist, targets TLR9 positive cells and activates both the innate and adaptive immune system. In subgroup analyses of a maintenance randomized phase II trial (NCT02200081) including SCLC patients who responded to first-line platinum-doublet chemotherapy, interesting results were found. Median OS was not significantly different for the total study population ( $N=102$, 279 days for lefitolimod, 272 days for the control arm, HR $1.27,95 \% \mathrm{Cl} 0.80-2.01, p=0.53)$, but results were promising although not significantly different in the predefined subgroup of COPD patients (median OS 316 vs 246 days, HR $0.54,95 \% \mathrm{Cl} 0.21-1.38$ ). Promising results were also found in the predefined subgroup of patients with baseline low number of activated B cells (median OS 284 vs 231 days, HR 0.59, 95\% Cl 0.29-1.21) [138].

\section{Conclusion}

SCLC is a tumor with a poor prognosis, mainly diagnosed in an advanced stage as screening is not effective due to its high aggressiveness. Smoking cessation is the best method to prevent SCLC development.

Despite aggressive treatment of early and locally advanced disease, SCLC often relapses. First-line chemotherapy provides good RRs in advanced disease, but PFS and OS are limited. Targetable molecular aberrations are very rare in SCLC and almost all attempts made so far have been unsuccessful, although Rova-T and anlotinib are more promising. New drugs such as immune checkpoint inhibition are promising in SCLC, especially in combination with chemotherapy, but still more data and better predictive markers are needed.

\section{Expert commentary}

The prognosis of most SCLC patients is still poor, despite the steps forward in SCLC molecular characterization, and the (small) improvements in systemic treatment.

The lack of identification of clear prognostic and predictive biomarkers has limited the advances in treatment efficacy. This has most likely determined the failure in the development of most compounds tested so far. One of the reasons that might have contributed is the absence of an adequate amount of tissue material for analysis, since the diagnosis is mostly by cytology. On the other hand, the complex tumor biology with the co-activation of several pathways and the rapid development of resistance is also a challenge. Moreover, tumor heterogeneity, not yet well studied for this particular lung cancer type, could play a key role in this disease and this needs to be further explored.

In this scenario, liquid biopsy could represent a solution to hopefully provide further data to better characterize and monitor this disease.

Due to its highly mutational profile and rapid growth pattern, immunotherapy combinations could be another step forward in SCLC treatment. The phase III IMpower133 study combining atezolizumab with carboplatin and etoposide is the first phase III trial in about 20 years reporting a significant improvement (although modest) in OS [133]. Multiple other combination trials are ongoing, but the main research focus should be defining which patients benefit most from a specific combination therapy (e.g. PD-(L)1 inhibition combined with chemotherapy, PD-(L)1 and CTLA4 combinations with or without chemotherapy, and other combinations). Particularly, toxicity should also be thoroughly evaluated.

Other challenges will be, both for LD and ED-SCLC, the identification of the best treatment sequence and the evaluation of the potential efficacy of rechallenging immunotherapy. Academic trials could represent the best way to test the sequential strategy in order to finally provide clinicians the support needed to treat patients in every-day clinic. The ultimate goal is to prolong OS, and maintain/improve quality of life, without a too high financial toxicity.

Crucial fields in the next future will also certainly be the control of paraneoplastic syndromes, quite frequent in these patients [110], as well as the control and treatment of brain metastases [139], very frequently present already at diagnosis, but also often a site of disease progression. Unfortunately, SCLC patients with brain metastases are underrepresented in clinical trials (e.g. only $8.5 \%$ brain metastases in the atezolizumab arm of the IMpower133 study) [133].

The achievements made so far with targeted agents are small, and most of the compounds tested did not shown any benefit in activity or efficacy $[28,70]$. More promising are combinations with DLL3-antibodies or PARPi that could potentially overcome mechanisms of resistance resulting hopefully in a meaningful clinical benefit.

The results of antiangiogenic drugs have been rather disappointing so far, but potential combinations with targeted agents and/or immunotherapy are currently tested in clinical trials, and results should be awaited before cutting off the development of these compounds in this tumor type. Hopefully the improved treatments in ED-SCLC also translate to improved survival in LD-SCLC when tested in this setting.

\section{Five-year view}

In the coming years, we expect the focus of clinical research to be on (1) predictive factors for immunotherapy, (2) the identification of mechanisms of resistance to immunotherapy and 
how to overcome them, and (3) the best treatment sequence strategies.

Moreover, preclinical and clinical research should focus on better understanding the crosstalk signaling pathways so as to finally manage targeted agents correctly.

\section{Key issues}

- SCLC patients usually have a small amount of tissue to be analyzed, limiting therefore translational research

- There is a clear lack of prognostic and predictive biomarkers in this rapidly evolving disease

- Targeted therapies have failed to improve outcome, although newer therapies such as PARPi and DLL3-antibodies are promising

- Immunotherapy combinations can improve long-term outcome in SCLC, but better predictive markers need to be identified so to develop the best treatment strategy and sequence

\section{Acknowledgments}

L. Hendriks was the recipient of the Diploma in Clinical and Translational Research in Oncology grant for the year 2017-2018.

\section{Funding}

This paper was not funded

\section{Declaration of interest}

L. Hendriks has recieved research funding from Roche and Boehringer Ingelheim, advisory board fees from Boehringer and BMS and travel reimbursement from Roche and BMS. M. Reck has recieved honoraria for lectures and consultancy from Roche, Abbvie, AstraZeneca, BMS, BoehringerIngelheim, Celgene, Lilly, MSD, Merck, Novartis, Pfizer. The authors have no other relevant affiliations or financial involvement with any organization or entity with a financial interest in or financial conflict with the subject matter or materials discussed in the manuscript. This includes employment, consultancies, honoraria, stock ownership or options, expert testimony, grants or patents received or pending, or royalties.

\section{References}

Papers of special note have been highlighted as either of interest $(\cdot)$ or of considerable interest (..) to readers.

1. Ferlay J, Soerjomataram I, Dikshit R, et al. Cancer incidence and mortality worldwide: sources, methods and major patterns in GLOBOCAN 2012. Int J Cancer. 2015;136:E359-86.

2. Lozano R, Naghavi M, Foreman $K$, et al. Global and regional mortality from 235 causes of death for 20 age groups in 1990 and 2010: a systematic analysis for the global burden of disease study 2010 . Lancet. 2012;380:2095-2128.

3. Torre LA, Siegel RL, Jemal A. Lung cancer statistics. Adv Exp Med Biol. 2016;893:1-19.

4. Torre LA, Siegel RL, Ward EM, et al. Global cancer incidence and mortality rates and trends-an update. Cancer Epidemiol Biomarkers Prev. 2016;25:16-27.

5. Ou SH, Ziogas A, Zell JA. Prognostic factors for survival in extensive stage small cell lung cancer (ED-SCLC): the importance of smoking history, socioeconomic and marital statuses, and ethnicity. J Thorac Oncol. 2009;4:37-43.
6. Pesch B, Kendzia B, Gustavsson P, et al. Cigarette smoking and lung cancer-relative risk estimates for the major histological types from a pooled analysis of case-control studies. Int J Cancer J Inter Du Cancer. 2012;131:1210-1219.

7. Huang R, Wei $Y$, Hung RJ, et al. Associated links among smoking, chronic obstructive pulmonary disease, and small cell lung cancer: a pooled analysis in the international lung cancer consortium. EBioMedicine. 2015;2:1677-1685.

8. Khuder SA, Mutgi AB. Effect of smoking cessation on major histologic types of lung cancer. Chest. 2001;120:1577-1583.

9. Team NLSTR, Aberle DR, Adams AM, et al. Reduced lung-cancer mortality with low-dose computed tomographic screening. N Engl J Med. 2011;365:395-409.

10. Silva M, Galeone C, Sverzellati N, et al. Screening with low-dose computed tomography does not improve survival of small cell lung cancer. J Thorac Oncol. 2016;11:187-193.

11. Aberle DR, DeMello $S$, Berg CD, et al. Results of the two incidence screenings in the national lung screening trial. $\mathrm{N}$ Engl J Med. 2013;369:920-931.

12. Fruh $M$, De Ruysscher $D$, Popat $S$, et al. Small-cell lung cancer (SCLC): ESMO clinical practice guidelines for diagnosis, treatment and follow-up. Ann oncol. 2013;24(Suppl 6):vi99-105.

13. Rossi A, Di Maio M, Chiodini P, et al. Carboplatin- or cisplatin-based chemotherapy in first-line treatment of small-cell lung cancer: the COCIS meta-analysis of individual patient data. J Clin Oncol. 2012;30:1692-1698.

14. O'Brien ME, Ciuleanu TE, Tsekov $\mathrm{H}$, et al. Phase III trial comparing supportive care alone with supportive care with oral topotecan in patients with relapsed small-cell lung cancer. J Clin Oncol. 2006;24:5441-5447.

15. Eckardt JR, von Pawel J, Pujol JL, et al. Phase III study of oral compared with intravenous topotecan as second-line therapy in small-cell lung cancer. J Clin Oncol. 2007;25:2086-2092.

16. Smit EF, Fokkema E, Biesma B, et al. A phase II study of paclitaxel in heavily pretreated patients with small-cell lung cancer. $\mathrm{Br} J$ Cancer. 1998;77:347-351.

17. Yamamoto N, Tsurutani J, Yoshimura N, et al. Phase II study of weekly paclitaxel for relapsed and refractory small cell lung cancer. Anticancer Res. 2006;26:777-781.

18. Pietanza MC, Kadota K, Huberman K, et al. Phase II trial of temozolomide in patients with relapsed sensitive or refractory small cell lung cancer, with assessment of methylguanine-DNA methyltransferase as a potential biomarker. Clin Cancer Res. 2012;18:1138-1145.

19. Zauderer MG, Drilon A, Kadota K, et al. Trial of a 5-day dosing regimen of temozolomide in patients with relapsed small cell lung cancers with assessment of methylguanine-DNA methyltransferase. Lung Cancer. 2014;86:237-240.

20. von Pawel J, Jotte R, Spigel DR, et al. Randomized phase III trial of amrubicin versus topotecan as second-line treatment for patients with small-cell lung cancer. J Clin Oncol. 2014;32:4012-4019.

21. Bordi $P$, Tiseo $M$, Barbieri $F$, et al. Gene mutations in small-cell lung cancer (SCLC): results of a panel of 6 genes in a cohort of Italian patients. Lung Cancer. 2014;86:324-328.

22. Lou G, Yu X, Song Z. Molecular profiling and survival of completely resected primary pulmonary neuroendocrine carcinoma. Clin Lung Cancer. 2017;18:e197-e201.

23. Shibata T, Kokubu A, Tsuta K, et al. Oncogenic mutation of PIK3CA in small cell lung carcinoma: a potential therapeutic target pathway for chemotherapy-resistant lung cancer. Cancer Lett. 2009;283:203-211.

24. Schultheis AM, Bos $M$, Schmitz K, et al. Fibroblast growth factor receptor 1 (FGFR1) amplification is a potential therapeutic target in small-cell lung cancer. Mod Pathol. 2014;27:214-221.

25. Byers LA, Wang J, Nilsson MB, et al. Proteomic profiling identifies dysregulated pathways in small cell lung cancer and novel therapeutic targets including PARP1. Cancer Discov. 2012;2:798-811.

26. Boldrini L, Ursino $S$, Gisfredi $S$, et al. Expression and mutational status of c-kit in small-cell lung cancer: prognostic relevance. Clin Cancer Res. 2004;10:4101-4108. 
27. Lawson MH, Cummings NM, Rassl DM, et al. Bcl-2 and beta1integrin predict survival in a tissue microarray of small cell lung cancer. Br J Cancer. 2010;103:1710-1715.

28. Sharp A, Bhosle J, Abdelraouf F, et al. Development of molecularly targeted agents and immunotherapies in small cell lung cancer. Eur J Cancer. 2016;60:26-39.

-. This review gives an overview of targetable alterations in SCLC.

29. George J, Lim JS, Jang SJ, et al. Comprehensive genomic profiles of small cell lung cancer. Nature. 2015;524:47-53.

30. Sabari JK, Lok BH, Laird JH, et al. Unravelling the biology of SCLC: implications for therapy. Nat Rev Clin Oncol. 2017;14:549-561.

31. Allison Stewart C, Tong P, Cardnell RJ, et al. Dynamic variations in epithelial-to-mesenchymal transition (EMT), ATM, and SLFN11 govern response to PARP inhibitors and cisplatin in small cell lung cancer. Oncotarget. 2017;8:28575-28587.

32. Peifer $M$, Fernandez-Cuesta $L$, Sos $M L$, et al. Integrative genome analyses identify key somatic driver mutations of small-cell lung cancer. Nat Genet. 2012;44:1104-1110.

33. Cardnell RJ, Feng Y, Mukherjee S, et al. Activation of the PI3K/mTOR pathway following PARP inhibition in small cell lung cancer. PLoS One. 2016;11:e0152584.

34. Hook KE, Garza SJ, Lira ME, et al. An integrated genomic approach to identify predictive biomarkers of response to the aurora kinase inhibitor PF-03814735. Mol Cancer Ther. 2012;11:710-719.

35. Sos ML, Dietlein F, Peifer $M$, et al. A framework for identification of actionable cancer genome dependencies in small cell lung cancer. Proc Natl Acad Sci USA. 2012;109:17034-17039.

36. Bruzzese F, Rocco M, Castelli $S$, et al. Synergistic antitumor effect between vorinostat and topotecan in small cell lung cancer cells is mediated by generation of reactive oxygen species and DNA damage-induced apoptosis. Mol Cancer Ther. 2009;8:3075-3087.

37. Palma JP, Wang YC, Rodriguez LE, et al. ABT-888 confers broad in vivo activity in combination with temozolomide in diverse tumors. Clin Cancer Res. 2009;15:7277-7290.

38. Camirand A, Pollak M. Co-targeting IGF-1R and c-kit: synergistic inhibition of proliferation and induction of apoptosis in H 209 small cell lung cancer cells. Br J Cancer. 2004;90:1825-1829.

39. Lochmann TL, Floros KV, Naseri M, et al. Venetoclax is effective in small-cell lung cancers with high BCL-2 expression. Clin Cancer Res. 2018;24:360-369.

40. Polley E, Kunkel M, Evans D, et al. Small cell lung cancer screen of oncology drugs, investigational agents, and gene and microRNA expression. J Natl Cancer Inst. 2016;108: djw122.

41. Rudin CM, Durinck S, Stawiski EW, et al. Comprehensive genomic analysis identifies SOX2 as a frequently amplified gene in small-cell lung cancer. Nat Genet. 2012;44:1111-1116.

42. Takebe N, Nguyen D, Yang SX. Targeting notch signaling pathway in cancer: clinical development advances and challenges. Pharmacol Ther. 2014;141:140-149.

43. Kunnimalaiyaan $M$, Chen $H$. Tumor suppressor role of Notch-1 signaling in neuroendocrine tumors. Oncologist. 2007;12:535-542.

44. Borromeo MD, Savage TK, Kollipara RK, et al. ASCL1 and NEUROD1 reveal heterogeneity in pulmonary neuroendocrine tumors and regulate distinct genetic programs. Cell Rep. 2016;16:1259-1272.

45. Henke RM, Meredith DM, Borromeo MD, et al. Ascl1 and Neurog2 form novel complexes and regulate Delta-like3 (DII3) expression in the neural tube. Dev Biol. 2009;328:529-540.

46. Semenova EA, Nagel R, Berns A. Origins, genetic landscape, and emerging therapies of small cell lung cancer. Genes Dev. 2015;29:1447-1462.

47. Saunders LR, Bankovich AJ, Anderson WC, et al. A DLL3-targeted antibody-drug conjugate eradicates high-grade pulmonary neuroendocrine tumor-initiating cells in vivo. Sci Transl Med. 2015;7:302ra136.

48. Gazdar AF, Carney DN, Nau MM, et al. Characterization of variant subclasses of cell lines derived from small cell lung cancer having distinctive biochemical, morphological, and growth properties. Cancer Res. 1985;45:2924-2930.
49. Carney DN, Gazdar AF, Bepler G, et al. Establishment and identification of small cell lung cancer cell lines having classic and variant features. Cancer Res. 1985;45:2913-2923.

50. George J, Walter V, Peifer M, et al. Integrative genomic profiling of large-cell neuroendocrine carcinomas reveals distinct subtypes of high-grade neuroendocrine lung tumors. Nat Commun. 2018;9:1048.

51. Dowlati A, Lipka MB, McColl K, et al. Clinical correlation of extensive-stage small-cell lung cancer genomics. Ann oncol. 2016;27:642-647.

52. Indovina P, Pentimalli F, Casini N, et al. RB1 dual role in proliferation and apoptosis: cell fate control and implications for cancer therapy. Oncotarget. 2015;6:17873-17890.

53. Hanahan D, Weinberg RA. The hallmarks of cancer. Cell. 2000;100:57-70.

54. Tanno S, Ohsaki $Y$, Nakanishi $K$, et al. Human small cell lung cancer cells express functional VEGF receptors, VEGFR-2 and VEGFR-3. Lung Cancer. 2004;46:11-19.

55. Lucchi M, Mussi A, Fontanini G, et al. Small cell lung carcinoma (SCLC): the angiogenic phenomenon. Eur J Cardio-Thorac Surg. 2002;21:1105-1110.

56. Nowak K, Rafat N, Belle S, et al. Circulating endothelial progenitor cells are increased in human lung cancer and correlate with stage of disease. Eur J Cardio-Thorac Surg. 2010;37:758-763.

57. Canadas I, Taus A, Villanueva X, et al. Angiopoietin-2 is a negative prognostic marker in small cell lung cancer. Lung Cancer. 2015;90:302-306

58. Salven $P$, Ruotsalainen $T$, Mattson $K$, et al. High pre-treatment serum level of vascular endothelial growth factor (VEGF) is associated with poor outcome in small-cell lung cancer. Int J Cancer. 1998;79:144-146.

59. Hasegawa Y, Takanashi S, Okudera K, et al. Vascular endothelial growth factor level as a prognostic determinant of small cell lung cancer in Japanese patients. Intern Med. 2005;44:26-34.

60. Mullen PJ, Yu R, Longo J, et al. The interplay between cell signalling and the mevalonate pathway in cancer. Nat Rev Cancer. 2016;16:718-731.

61. Khanzada UK, Pardo OE, Meier C, et al. Potent inhibition of smallcell lung cancer cell growth by simvastatin reveals selective functions of Ras isoforms in growth factor signalling. Oncogene. 2006;25:877-887.

62. Michael M, Babic B, Khokha R, et al. Expression and prognostic significance of metalloproteinases and their tissue inhibitors in patients with small-cell lung cancer. J Clin Oncol. 1999;17:18021808.

63. Brown PD, Giavazzi R. Matrix metalloproteinase inhibition: a review of anti-tumour activity. Ann Oncol. 1995;6:967-974.

64. Brown PD. Matrix metalloproteinase inhibitors: a novel class of anticancer agents. Adv Enzyme Regul. 1995;35:293-301.

65. Goldenberg DM, Cardillo TM, Govindan SV, et al. Trop-2 is a novel target for solid cancer therapy with sacituzumab govitecan (IMMU-132), an antibody-drug conjugate (ADC). Oncotarget. 2015;6:22496-22512.

66. Lee SM, Woll PJ, Rudd R, et al. Anti-angiogenic therapy using thalidomide combined with chemotherapy in small cell lung cancer: a randomized, double-blind, placebo-controlled trial. J Natl Cancer Inst. 2009;101:1049-1057.

67. Arnold AM, Seymour L, Smylie M, et al. Phase II study of vandetanib or placebo in small-cell lung cancer patients after complete or partial response to induction chemotherapy with or without radiation therapy: national cancer institute of canada clinical trials group study BR.20. J Clin Oncol. 2007;25:4278-4284.

68. Seckl MJ, Ottensmeier $\mathrm{CH}$, Cullen $\mathrm{M}$, et al. Multicenter, phase III, randomized, double-blind, placebo-controlled trial of pravastatin added to first-line standard chemotherapy in small-cell lung cancer (LUNGSTAR). J Clin Oncol. 2017;35:1506-1514.

69. Shepherd FA, Giaccone G, Seymour L, et al. Prospective, randomized, double-blind, placebo-controlled trial of marimastat after response to first-line chemotherapy in patients with small-cell lung cancer: a trial of the national cancer institute of canada-clinical 
trials group and the european organization for research and treatment of cancer. J Clin Oncol. 2002;20:4434-4439.

70. Baize N, Monnet I, Greillier L, et al. Second-line treatments of smallcell lung cancers. Expert Rev Anticancer Ther. 2017;17:1033-1043.

.- This review summarizes all recent second-line treatments in SCLC up till 2017.

71. Tentori L, Graziani G. Chemopotentiation by PARP inhibitors in cancer therapy. Pharmacol Res. 2005;52:25-33.

72. Pietanza MC, Waqar SN, Krug LM, et al. Randomized, double-blind, phase ii study of temozolomide in combination with either veliparib or placebo in patients with relapsed-sensitive or refractory small-cell lung cancer. J Clin Oncol. 2018;36(23):2386 2304.

73. Tarhini A, Kotsakis A, Gooding W, et al. Phase II study of everolimus (RAD001) in previously treated small cell lung cancer. Clin Cancer Res. 2010;16:5900-5907.

74. Owonikoko TK, Dahlberg SE, Khan SA, et al. A phase 1 safety study of veliparib combined with cisplatin and etoposide in extensive stage small cell lung cancer: A trial of the ECOG-ACRIN cancer research group (E2511). Lung Cancer. 2015;89:66-70.

75. Lallo A, Frese KK, Morrow $C$, et al. The combination of the PARP inhibitor olaparib and the Wee1 inhibitor AZD1775 as a new therapeutic option for small cell lung cancer. Clin Cancer Res. 2018;24 (20):5153-5164.

76. Sen T, Tong P, Stewart CA, et al. CHK1 inhibition in small-cell lung cancer produces single-agent activity in biomarker-defined disease subsets and combination activity with cisplatin or olaparib. Cancer Res. 2017;77:3870-3884.

77. Rudin CM, Pietanza MC, Bauer TM, et al. Rovalpituzumab tesirine, a DLL3-targeted antibody-drug conjugate, in recurrent small-cell lung cancer: a first-in-human, first-in-class, open-label, phase 1 study. Lancet Oncol. 2017;18:42-51.

.. This is the first Rova-T trial published.

78. Carbone DP, Morgenstern D, Le Moulec S, et al. Efficacy and safety of rovalpituzumab tesirine in patients with DLL3-expressing, $\geq 3 \mathrm{rd}$ line small cell lung cancer: results from the phase 2 TRINITY study. J clin oncol. 2018;36:abstr 8507.

\section{- Although only abstract form, this is the first phase II trial with} Rova-T.

79. Gray JE, Heist RS, Starodub AN, et al. Therapy of small cell lung cancer (SCLC) with a topoisomerase-l-inhibiting Antibody-Drug Conjugate (ADC) Targeting Trop-2, Sacituzumab Govitecan. Clin Cancer Res. 2017;23:5711-5719.

80. Edelman MJ, Clamon G, Kahn D, et al. Targeted radiopharmaceutical therapy for advanced lung cancer: phase I trial of rhenium Re188 P2045, a somatostatin analog. J Thorac Oncol. 2009;4:1550-1554.

81. Cheng Y, Wang Q, Li K, et al. Anlotinib as third-line or further-line treatment in relapsed SCLC: a multicentre, randomized, doubleblind phase 2 trial. WCLC. 2018;Toronto:abstr OA13.03.

82. Hwang DH, Sun H, Rodig SJ, et al. Myc protein expression correlates with MYC amplification in small-cell lung carcinoma. Histopathology. 2015;67:81-89.

83. Alves Rde C, Meurer RT, Roehe AV. MYC amplification is associated with poor survival in small cell lung cancer: a chromogenic in situ hybridization study. J Cancer Res Clin Oncol. 2014;140:2021-2025.

84. Vader G, Lens SM. The Aurora kinase family in cell division and cancer. Biochim Biophys Acta. 2008;1786:60-72.

85. Melichar B, Adenis A, Lockhart AC, et al. Safety and activity of alisertib, an investigational aurora kinase $A$ inhibitor, in patients with breast cancer, small-cell lung cancer, non-small-cell lung cancer, head and neck squamous-cell carcinoma, and gastro-oesophageal adenocarcinoma: a five-arm phase 2 study. Lancet Oncol. 2015;16:395-405.

86. Niu $H$, Shin $H$, Gao F, et al. Aurora a functional single nucleotide polymorphism (SNP) correlates with clinical outcome in patients with advanced solid tumors treated with alisertib, an investigational aurora a kinase inhibitor. EBioMedicine. 2017;25:50-57.

87. Owonikoko TK, Nackaerts K, Csoszi T, et al. OA05.05 randomized phase 2 study: alisertib (MLN8237) or Placebo + Paclitaxel as Second-Line Therapy for Small-Cell Lung Cancer (SCLC). J Thorac Oncol. 2017;12:S261-S2.
88. Helfrich BA, Kim J, Gao D, et al. Barasertib (AZD1152), a small molecule Aurora B inhibitor, inhibits the growth of SCLC cell lines in vitro and in vivo. Mol Cancer Ther. 2016;15:2314-2322.

89. Calvo E, Moreno V, Flynn M, et al. Antitumor activity of lurbinectedin (PM01183) and doxorubicin in relapsed small-cell lung cancer: results from a phase I study. Ann oncol. 2017;28:2559-2566.

90. Pietanza MC, Litvak AM, Varghese AM, et al. A phase I trial of the hedgehog inhibitor, sonidegib (LDE225), in combination with etoposide and cisplatin for the initial treatment of extensive stage small cell lung cancer. Lung Cancer. 2016;99:23-30.

91. Belani CP, Dahlberg SE, Rudin CM, et al. Vismodegib or cixutumumab in combination with standard chemotherapy for patients with extensive-stage small cell lung cancer: a trial of the ECOG-ACRIN Cancer Research Group (E1508). Cancer. 2016;122:2371-2378.

92. Pujol JL, Lavole A, Quoix E, et al. Randomized phase II-III study of bevacizumab in combination with chemotherapy in previously untreated extensive small-cell lung cancer: results from the IFCT0802 trialdagger. Ann oncol. 2015;26:908-914.

93. Spigel DR, Townley PM, Waterhouse DM, et al. Randomized phase II study of bevacizumab in combination with chemotherapy in previously untreated extensive-stage small-cell lung cancer: results from the SALUTE trial. J Clin Oncol. 2011;29:2215-2222.

94. Tiseo M, Boni L, Ambrosio F, et al. Italian, multicenter, phase iii, randomized study of cisplatin plus etoposide with or without bevacizumab as first-line treatment in extensive-disease small-cell lung cancer: the GOIRC-AIFA FARM6PMFJM trial. J Clin Oncol. 2017;35:1281-1287.

95. Han JY, Kim HY, Lim KY, et al. A phase II study of nintedanib in patients with relapsed small cell lung cancer. Lung Cancer. 2016;96:108-112.

96. Ready $\mathrm{NE}$, Pang $\mathrm{HH}, \mathrm{Gu} \mathrm{L}$, et al. Chemotherapy with or without maintenance sunitinib for untreated extensive-stage small-cell lung cancer: a randomized, double-blind, placebo-controlled phase II study-CALGB 30504 (alliance). J Clin Oncol. 2015;33:1660-1665.

97. Allen JW, Moon J, Redman M, et al. Southwest oncology group S0802: a randomized, phase II trial of weekly topotecan with and without ziv-aflibercept in patients with platinum-treated small-cell lung cancer. J Clin Oncol. 2014;32:2463-2470.

98. Mountzios G, Emmanouilidis C, Vardakis N, et al. Paclitaxel plus bevacizumab in patients with chemoresistant relapsed small cell lung cancer as salvage treatment: a phase II multicenter study of the hellenic oncology research group. Lung Cancer. 2012;77:146-150.

99. Spigel DR, Waterhouse DM, Lane S, et al. Efficacy and safety of oral topotecan and bevacizumab combination as second-line treatment for relapsed small-cell lung cancer: an open-label multicenter single-arm phase II study. Clin Lung Cancer. 2013;14:356-363.

100. Trafalis DT, Alifieris C, Stathopoulos GP, et al. Phase II study of bevacizumab plus irinotecan on the treatment of relapsed resistant small cell lung cancer. Cancer Chemother Pharmacol. 2016;77:713-722.

101. Shinmura $\mathrm{K}$, Iwaizumi $\mathrm{M}$, Igarashi $\mathrm{H}$, et al. Induction of centrosome amplification and chromosome instability in p53-deficient lung cancer cells exposed to benzo[a]pyrene diol epoxide (B[a]PDE). J Pathol. 2008;216:365-374.

102. Wistuba II, Behrens C, Virmani AK, et al. High resolution chromosome $3 p$ allelotyping of human lung cancer and preneoplastic/ preinvasive bronchial epithelium reveals multiple, discontinuous sites of $3 p$ allele loss and three regions of frequent breakpoints. Cancer Res. 2000;60:1949-1960.

103. Wistuba II, Gazdar AF. Lung cancer preneoplasia. Annu Rev Pathol. 2006;1:331-348.

104. Hussain SP, Amstad P, Raja K, et al. Mutability of p53 hotspot codons to benzo(a)pyrene diol epoxide (BPDE) and the frequency of p53 mutations in nontumorous human lung. Cancer Res. 2001;61:6350-6355.

105. Brambilla E, Gazzeri S, Lantuejoul S, et al. p53 mutant immunophenotype and deregulation of p53 transcription pathway $(\mathrm{BCl} 2, \mathrm{Bax}$, and Waf1) in precursor bronchial lesions of lung cancer. Clin Cancer Res. 1998;4:1609-1618. 
106. Roberts SA, Lawrence MS, Klimczak LJ, et al. An APOBEC cytidine deaminase mutagenesis pattern is widespread in human cancers. Nat Genet. 2013;45:970-976.

107. Alexandrov LB, Nik-Zainal S, Wedge DC, et al. Signatures of mutational processes in human cancer. Nature. 2013;500:415-421.

108. Yu H, Batenchuk C, Badzio A, et al. PD-L1 expression by two complementary diagnostic assays and mrna in situ hybridization in small cell lung cancer. J Thorac Oncol. 2017;12:110-120.

109. Borghaei H, Paz-Ares L, Horn L, et al. Nivolumab versus docetaxel in advanced nonsquamous non-small-cell lung cancer. $\mathrm{N}$ Engl J Med. 2015;373:1627-1639.

110. Gozzard P, Woodhall M, Chapman C, et al. Paraneoplastic neurologic disorders in small cell lung carcinoma: A prospective study. Neurology. 2015;85:235-239.

111. Wang W, Hodkinson P, McLaren F, et al. Histologic assessment of tumor-associated $\mathrm{CD} 45(+)$ cell numbers is an independent predictor of prognosis in small cell lung cancer. Chest. 2013;143:146-151.

112. Koyama K, Kagamu H, Miura S, et al. Reciprocal CD4+ T-cell balance of effector CD62Llow CD4+ and CD62LhighCD25+ CD4+ regulatory T cells in small cell lung cancer reflects disease stage. Clin Cancer Res. 2008;14:6770-6779.

113. Tani T, Tanaka K, Idezuka J, et al. Regulatory T cells in paraneoplastic neurological syndromes. J Neuroimmunol. 2008;196:166-169.

114. Reck M, Rodriguez-Abreu D, Robinson AG, et al. Pembrolizumab versus chemotherapy for PD-L1-positive non-small-cell lung cancer. N Engl J Med. 2016:375:1823-1833.

115. Brahmer J, Reckamp KL, Baas $P$, et al. Nivolumab versus docetaxel in advanced squamous-cell non-small-cell lung cancer. $N$ Engl J Med. 2015;373:123-135.

116. Herbst RS, Baas P, Kim DW, et al. Pembrolizumab versus docetaxel for previously treated, PD-L1-positive, advanced non-small-cell lung cancer (KEYNOTE-010): a randomised controlled trial. Lancet. 2016;387:1540-1550.

117. Antonia SJ, Villegas A, Daniel D, et al. Durvalumab after chemoradiotherapy in stage iii non-small-cell lung cancer. N Engl J Med. 2017;377:1919-1929.

118. Giaccone G, Debruyne C, Felip E, et al. Phase III study of adjuvant vaccination with Bec2/bacille calmette-guerin in responding patients with limited-disease small-cell lung cancer (European organisation for research and treatment of cancer 08971-08971b; silva study). J Clin Oncol. 2005;23:6854-6864.

119. Krug LM, Ragupathi G, Hood C, et al. Vaccination of patients with small-cell lung cancer with synthetic fucosyl GM-1 conjugated to keyhole limpet hemocyanin. Clin Cancer Res. 2004;10:6094-6100.

120. Krug LM, Ragupathi G, Hood C, et al. Immunization with N-propionyl polysialic acid-KLH conjugate in patients with small cell lung cancer is safe and induces IgM antibodies reactive with SCLC cells and bactericidal against group B meningococci. Cancer Immunol Immunother. 2012;61:9-18.

121. Zarogoulidis K, Ziogas $\mathrm{E}$, Boutsikou $\mathrm{E}$, et al. Immunomodifiers in combination with conventional chemotherapy in small cell lung cancer: a phase II, randomized study. Drug Des Devel Ther. 2013;7:611-617.

122. Terazaki Y, Yoshiyama K, Matsueda S, et al. Immunological evaluation of personalized peptide vaccination in refractory small cell lung cancer. Cancer Sci. 2012;103:638-644.

123. Sakamoto S, Yamada T, Terazaki Y, et al. Feasibility study of personalized peptide vaccination for advanced small cell lung cancer. Clin Lung Cancer. 2017;18:e385-e94.

124. Antonia SJ, Mirza N, Fricke I, et al. Combination of p53 cancer vaccine with chemotherapy in patients with extensive stage small cell lung cancer. Clin Cancer Res. 2006;12:878-887.
125. Pillai RN, Aisner J, Dahlberg SE, et al. Interferon alpha plus 13-cisretinoic acid modulation of $\mathrm{BCL}-2$ plus paclitaxel for recurrent smallcell lung cancer (SCLC): an eastern cooperative oncology group study (E6501). Cancer Chemother Pharmacol. 2014;74:177-183.

126. Reck M, Luft A, Szczesna A, et al. Phase III randomized trial of ipilimumab plus etoposide and platinum versus placebo plus etoposide and platinum in extensive-stage small-cell lung cancer. J Clin Oncol. 2016;34:3740-3748.

- Although the trial failed to meet its primary end point, this is the first phase III trial evaluating checkpoint inhibition in SCLC.

127. Ott PA, Elez E, Hiret $S$, et al. Pembrolizumab in patients with extensive-stage small-cell lung cancer: results from the Phase $\mathrm{Ib}$ KEYNOTE-028 study. J Clin Oncol. 2017;35:3823-3829.

128. Gadgeel SM, Pennell NA, Fidler MJ, et al. Phase II study of maintenance pembrolizumab in patients with extensive-stage small cell lung cancer (SCLC). J Thorac Oncol. 2018;13(9):1393-1399.

- This is the first fully published phase II trial with PD-1 inhibition in SCLC.

129. Chung H, Lopez-Martin JA, Kao SC, et al. Phase 2 study of pembrolizumab in advanced small-cell lung cancer (SCLC): KEYNOTE158. J Clin Oncol. 2018;36:abstr 8506.

130. Goldman JW, Dowlati A, Antonia S, et al. Safety and antitumor activity of durvalumab monotherapy in patients with pretreated extensive disease small-cell lung cancer (ED-SCLC). J Clin Oncol. 2018;36:abstr 8518.

131. Pujol JL, Greillier L, Audigier-Valette C, et al. A randomized noncomparative phase II study of anti-PD-L1 ATEZOLIZUMAB or chemotherapy as second-line therapy in patients with small cell lung cancer: results from the IFCT-1603 Trial. Ann Oncol. 2018;29 (suppl_8):viii596-viii602.

132. Rivalland G, Walkiewicz M, Wright G, et al. Small cell lung cancer: the immune microenvironment and prognostic impact of checkpoint expression. J Clin Oncol. 2017;35:abstract 8569.

133. Horn L, Mansfield AS, Szczesna A, et al. First-line atezolizumab plus chemotherapy in extensive-stage small-cell lung cancer. N Engl J Med. sep 25 2018. epub ahead of print. DOI:10.1056/NEJMoa18090964

.• This is the first positive phase III chemotherapy-immunotherapy trial in SCLC.

134. Antonia SJ, Lopez-Martin JA, Bendell J, et al. Nivolumab alone and nivolumab plus ipilimumab in recurrent small-cell lung cancer (CheckMate 032): a multicentre, open-label, phase $1 / 2$ trial. Lancet Oncol. 2016;17:883-895.

135. Hellman M, Ott PA, Zugazagoitia J, et al. Nivolumab (nivo) \pm ipilimumab (ipi) in advanced small-cell lung cancer (SCLC): first report of a randomized expansion cohort from CheckMate 032. J Clin Oncol. 2017;35:abstract 8503.

136. Antonia S, Callahan MK, Awad MM, et al. OA 07.03a - impact of tumor mutation burden on the efficacy of nivolumab or nivolumab + ipilimumab in small cell lung cancer: an exploratory analysis of checkmate 032. J Thorac Oncol. 2017;11:abstrOA 07.3a.

137. Bondarenko I, Juan-Vidal O, Pajkos G, et al. Preliminary efficacy of durvalumab plus tremelimumab in platinum-refractory/resistant ED-SCLC from Arm A of the Phase II BALTIC study. Ann oncol. 2018;29(suppl_8):viii596-viii602.

138. Thomas M, Ponce Aix S, Navarro Mendivil A, et al. 15270 - Top-line data from the randomized phase 2 IMPULSE study in small-cell lung cancer $(\mathrm{SCLC})$ : immunotherapeutic maintenance treatment with lefitolimod. Ann Oncol. 2017;28:v539-v42.

139. Pechoux CL, Sun A, Slotman BJ, et al. Prophylactic cranial irradiation for patients with lung cancer. Lancet Oncol. 2016;17:e277-e93. 